BMC

Evolutionary Biology

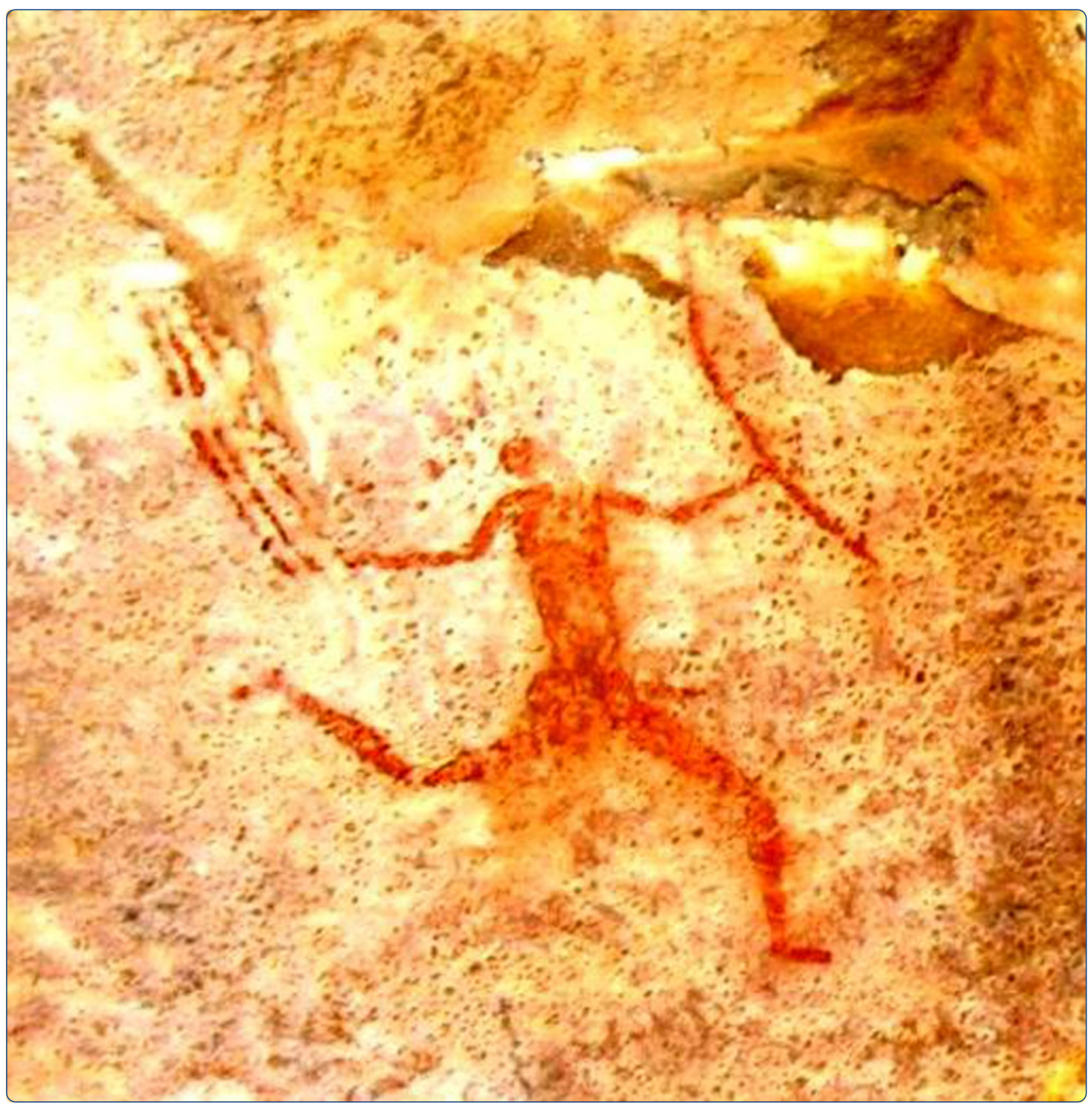

\title{
MtDNA control region variation affirms diversity and deep sub-structure in populations from southern Africa
}

Schlebusch et al. 


\title{
MtDNA control region variation affirms diversity and deep sub-structure in populations from southern Africa
}

\author{
Carina M Schlebusch ${ }^{1,2^{*}}$, Marlize Lombard ${ }^{3}$ and Himla Soodyall ${ }^{1}$
}

\begin{abstract}
Background: The current San and Khoe populations are remnant groups of a much larger and widely dispersed population of hunter-gatherers and pastoralists, who had exclusive occupation of southern Africa before the influx of Bantu-speakers from $2 \mathrm{ka}$ ( $\mathrm{ka}=$ kilo annum [thousand years] old/ago) and sea-borne immigrants within the last 350 years. Here we use mitochondrial DNA (mtDNA) to examine the population structure of various San and Khoe groups, including seven different Khoe-San groups (Ju/hoansi, !Xun, /Gui+//Gana, Khwe, \#Khomani, Nama and Karretjie People), three different Coloured groups and seven other comparative groups. MtDNA hyper variable segments I and II (HVS I and HVS II) together with selected mtDNA coding region SNPs were used to assign 538 individuals to 18 haplogroups encompassing 245 unique haplotypes. Data were further analyzed to assess haplogroup histories and the genetic affinities of the various San, Khoe and Coloured populations. Where possible, we tentatively contextualize the genetic trends through time against key trends known from the archaeological record.

Results: The most striking observation from this study was the high frequencies of the oldest mtDNA haplogroups ( LOd and LOk) that can be traced back in time to $100 \mathrm{ka}$, found at high frequencies in Khoe-San and sampled Coloured groups. Furthermore, the LOd/k sub-haplogroups were differentially distributed in the different Khoe-San and Coloured groups and had different signals of expansion, which suggested different associated demographic histories. When populations were compared to each other, San groups from the northern parts of southern Africa (Ju speaking: !Xun, Ju/'hoansi and Khoe-speaking: /Gui+//Gana) grouped together and southern groups (historically Tuu speaking: \#Khomani and Karretjie People and some Coloured groups) grouped together. The Khoe group (Nama) clustered with the southern Khoe-San and Coloured groups. The Khwe mtDNA profile was very different from other Khoe-San groups with high proportions of Bantu-speaking admixture but also unique distributions of other mtDNA lineages.
\end{abstract}

Conclusions: On the whole, the research reported here presented new insights into the multifaceted demographic history that shaped the existing genetic landscape of the Khoe-San and Coloured populations of southern Africa.

Keywords: mtDNA, LOd, LOk, Khoisan-speakers, Khoe-San, San, Southern Africa, African history, Mitochondrial haplogroup

\footnotetext{
* Correspondence: cschlebu@gmail.com

${ }^{1}$ Human Genomic Diversity and Disease Research Unit, Division of Human Genetics, School of Pathology, Faculty of Health Sciences, University of the Witwatersrand and the National Health Laboratory Service, Johannesburg 2000, South Africa

${ }^{2}$ Department of Evolutionary Biology, Evolutionary Biology Centre, Uppsala University, Norbyvägen 18D, Uppsala, SE 752 36, Sweden

Full list of author information is available at the end of the article
}

\section{Biomed Central}

(c) 2013 Schlebusch et al.; licensee BioMed Central Ltd. This is an Open Access article distributed under the terms of the Creative Commons Attribution License (http://creativecommons.org/licenses/by/2.0), which permits unrestricted use, distribution, and reproduction in any medium, provided the original work is properly cited. 


\section{Background}

The term "Khoe-San" represents groups with two distinct lifeways, the Khoi (old Nama word) or Khoe (modern Nama word), who were traditionally the pastoralist groups and the San, which included the hunter-gatherer groups [1,2]. This grouping was made according to the conventional division that existed between hunter-gatherers and pastoralists at the time of colonization. Whether the grouping is a true reflection of subdivision remains a topic of debate [3,4]. The current distribution of Khoe-San groups comprises a wide geographic region from southern Angola in the north to the Western Cape Province (South Africa) in the south. They live among, and to some extent are admixed with, the various surrounding Bantu-speaking populations [3,5,6]. Linguistically, Khoe-San groups are divided into northern Khoisan-speaking groups (Ju division) and southern Khoisan-speaking groups (Tuu division) with an additional linguistic group (Khoe-Kwadi) associated with some Khoe-speaking San groups in Botswana and the Khoe herders of South Africa and Namibia (such as the Nama) $[7,8]$.

Mitochondrial DNA (mtDNA) studies showed that Khoe-San populations tend to carry unique and more divergent lineages than the mtDNA lineages associated with Bantu-speakers [9-12]. In fact, the deepest mtDNA clades known among modern humans (LOd and LOk), are found commonly and at their highest frequencies in the Khoe-San. Only few studies thus far focused on the maternal genetic history of the Khoe-San [9-12] (Additional file 1: Table S1). These studies covered only three groups of San, including, the two Ju-speaking groups: the !Xun that were originally from Angola (now located in Platfontein, South Africa [13]) and the linguistically closely related Ju/hoansi (from northern Botswana and Namibia), and the Khoe-speaking San group, the Khwe (also originally from Angola but now located in Platfontein). All three of these groups were originally from either Angola or northern Namibia, positioning them in the northern parts of the original distribution of the Khoe-San. This left a gap, with no studies conducted on groups representative of the southern San and Khoe, that we aim to start addressing with this contribution. It is, however, becoming increasingly difficult to study the history of the Khoe-San, as groups are losing their cultural identities, socio-economies and languages, and are integrating into surrounding groups.

Although the San and Khoe groups are rather small populations today, their genetic contribution to some of the Coloured populations of South Africa has been substantial [14-16]. To understand the underlying genetic factors in an admixed population such as the Coloured groups of South Africa, it is essential to study the parental populations. By examining the mtDNA variation in several San and Khoe groups from different regions in southern Africa as well as three selected Coloured groups from South Africa, we provide insight into how females have contributed to the genetic affinities of the Khoe-San and some Coloured groups, as well as an opportunity to further examine the evolutionary history of mtDNA haplogroups LOd and L0k.

\section{Results}

The 538 samples used in mtDNA analysis (Table 1, Additional file 2: Figure S1) were first classified into macro-haplogroups using a minisequencing method, and finer scale classification was achieved by analyzing HVS-I and II sequences. A total of $1124 \mathrm{bp}$ in a combined HVS-I and II were analyzed and there were 205 (18.2\%) variable positions in the combined sequence (HVS-I had $21.3 \%$ and HVS-II had 15.1\%). The transition:transversion ratio was 5.6:1. Insertions were observed at four positions $(291,455,523,573)$, whereas deletions occurred at seven positions (16183, 16179, 16325, 247, 249, 498, 523). All deletions involved 1 bp except the 523 region of HVS-II that contained an "AC" repeat motif that were inserted or deleted in several sequences. Insertions involved $1 \mathrm{bp}$ insertions at 291 and 455; one sequence had a 2 bp insertion at 455. All insertions in the poly $\mathrm{C}$ repeat track at position 568-573 where taken as a 1 bp $C$ insertion.

The 538 sequences were resolved into 18 haplogroups encompassing 245 haplotypes (Figure 1 and Additional file 2: Figure S2). Haplogroups other than LOd were found at very low frequencies in the total sample group (no other haplogroup was found at a frequency $>7 \%$ ). High frequencies of these non-LOd haplogroups were mostly seen in the comparative groups and not in the Khoe-San or sampled Coloured groups. L0d was the commonest haplogroup in the total sample $(59 \%)$ and had high frequencies in all of the Khoe-San and Coloured groups ranging in frequency from $45 \%$ in the Cape Coloured to $100 \%$ in the Karretjie People (see [17] for further information on this population group).

The association of the HVS haplotypes within their main haplogroups was assessed using maximum likelihood trees (Additional file 2: Figures S3a and b) and parsimony based network analysis (Figure 2). Alignments and phylogenies were submitted to treeBASE (Access at: http://purl.org/phylo/treebase/phylows/study/TB2:S13870? format $=\mathrm{html}$ ). Most haplogroups and sub-haplogroups grouped together on the tree; however, within the haplogroups L3, L4, M, N and R, the tree lacked structure. Thus, for certain haplogroups, the lack of variation in the HVS-I and II necessitate the use of coding region variation to indicate and direct the overall classification and structure of haplogroups (as was done using the minisequencing method). 
Table 1 Sample group details

\begin{tabular}{|c|c|c|c|c|c|c|c|}
\hline Group name & $\begin{array}{l}\text { Group } \\
\text { code }\end{array}$ & Main group & $\begin{array}{l}\text { Language } \\
\text { grouping }\end{array}$ & $\begin{array}{l}\text { Place of sampling } \\
\text { (Country) }\end{array}$ & $\begin{array}{l}\text { Place of origin if different } \\
\text { from place of sampling }\end{array}$ & $\mathrm{N}$ & $\begin{array}{c}\text { Traditional } \\
\text { subsistence }\end{array}$ \\
\hline Karoo Coloured & $\mathrm{COL}$ & Coloured & Mixed & Colesberg (SA) & & 77 & Mixed \\
\hline Cape Coloured & CAC & Coloured & Mixed & Wellington (SA) & & 20 & Mixed \\
\hline $\begin{array}{l}\text { Northern Cape } \\
\text { Coloured }\end{array}$ & CNC & Coloured & Mixed & Askham (SA) & & 40 & Mixed \\
\hline Karretjie people & KAR & Khoe-San & $\begin{array}{l}\text { Descendents of Tuu } \\
\text { speakers }\end{array}$ & Colesberg (SA) & & 30 & $\begin{array}{c}\text { Hunter-gatherer and } \\
\text { Herder }\end{array}$ \\
\hline \#Khomani & $\mathrm{KHO}$ & Khoe-San & $\begin{array}{l}\text { Descendents of Tuu } \\
\text { speakers }\end{array}$ & Askham (SA) & & 57 & $\begin{array}{c}\text { Hunter-gatherer and } \\
\text { Herder }\end{array}$ \\
\hline //Xegwi * & $X E G *$ & Khoe-San* & $\begin{array}{l}\text { Descendents of Tuu } \\
\text { speakers }\end{array}$ & Chrissiesmeer (SA) & & 3 & Hunter-gatherer \\
\hline Duma San * & DUM * & Khoe-San* & $\begin{array}{l}\text { Descendents of Tuu } \\
\text { speakers }\end{array}$ & Underberg (SA) & & 1 & Hunter-gatherer \\
\hline Nama & NAM & Khoe-San & Khoe (KhoeKhoe) & Windhoek (NM) & & 28 & Herder \\
\hline $\begin{array}{l}\text { /Gui, //Gana and } \\
\text { Kgalagari }\end{array}$ & GUG & Khoe-San & Khoe (Kalahari-Khoe) & $\begin{array}{l}\text { Kutse Game reserve } \\
\text { (BT) }\end{array}$ & & 22 & $\begin{array}{c}\text { Hunter-gatherer and } \\
\text { Farmer }\end{array}$ \\
\hline Naro * & $N A R *$ & Khoe-San* & Khoe (Kalahari-Khoe) & Johannesburg (SA) & Ghanzi (BT) & 2 & Hunter-gatherer \\
\hline Ju/'hoansi & $\mathrm{JOH}$ & Khoe-San & Ju & Tsumkwe (NM) & & 42 & Hunter-gatherer \\
\hline !Xun & XUN & Khoe-San & Ju & $\begin{array}{l}\text { Omega camp (NM) and } \\
\text { Schmidtsdrift (SA) }\end{array}$ & Menongue (AN) & 49 & Hunter-gatherer \\
\hline Khwe & KWE & Khoe-San & Khoe (Kalahari-Khoe) & $\begin{array}{l}\text { Omega camp (NM) and } \\
\text { Schmidtsdrift (SA) }\end{array}$ & Caprivi Strip (NM) & 18 & Hunter-gatherer \\
\hline Manyanga & DRC & Bantu-speaker & Bantu (central) & Luozi (DRC) & & 14 & Farmer \\
\hline Herero & HER & Bantu-speaker & Bantu (southwestern) & Windhoek (NM) & & 15 & Farmer and Herder \\
\hline Sotho, Tswana & SOT & Bantu-speaker & Bantu (southeastern) & Various (SA) & & 22 & Farmer \\
\hline Swazi * & SWZ * & Bantu-speaker* & Bantu (southeastern) & Chrissiesmeer (SA) & & 5 & Farmer \\
\hline Zulu, Xhosa & ZUX & Bantu-speaker & Bantu (southeastern) & Various (SA) & & 36 & Farmer \\
\hline Afrikaner & AFR & Non-African & Non-African & Various (SA) & & 21 & Mixed \\
\hline European & EUR & Non-African & Non-African & Various (SA) & Europe and Canada & 11 & Mixed \\
\hline Indian & IND & Non-African & Non-African & Various (SA) & & 25 & Mixed \\
\hline Total & & & & & & 538 & Mixed \\
\hline
\end{tabular}

AN - Angola.

BT - Botswana.

DRC - Democratic Republic of Congo.

NM - Namibia.

SA - South Africa.

* Small groups of individuals not included in group-wise analyses but included as individuals in network, tree and haplogroups assignments.

\section{Evolutionary history of mtDNA haplotypes in haplogroups} LOd/k

MtDNA haplotypes within sub-haplogroups belonging to the L0 clade were clearly associated in networks and trees (Figure 2 and Additional file 2: Figure S3, respectively). The Khoe-San associated haplogroups LOd and LOK were distributed at different frequencies in the different Khoe-San groups (Figure 3 and Additional file 2: Figure S4). Coalescent times (Time to Most Recent Common Ancestors - TMRCA) for all the LOd/k subgroups, and times at which their lineages diverged from the other lineages, were calculated from the network (Table 2, Additional file 1: Table S2, and Additional file 2: Figure S5). Although several studies have estimated
mtDNA mutation rates (Additional file 1: Table S2), we used the mutation rate suggested by Ward et al. [18] in the present study (this rate is very similar to the rate used by Soares et al., [19] for the combined HVS I and II, see Additional file 3: Supplementary methods).

Haplotypes within LOd/k found in the southern-San/ Coloured/Khoe groups (KAR, COL, CAC, KHO, CNC, NAM) were clearly distinguished from those found in the San groups located north of them (GUG, JOH, XUN) (Additional file 2: Figure S4, see Table 1 for population labels). Contour plots, visualizing the geographic distributions of the LOd/k subgroups (Figure 4 and Additional file 2: Figure S6) showed that certain sub-haplogroups (LOd3, LOd2a, LOd1b) had higher frequencies in the 
south; others had a more intermediate and central distribution (LOd2c and LOd1a), while some had higher frequencies in the north (LOk1). LOd1c showed a bimodal distribution pattern (Figure 4), and the sub-haplogroup LOd1c1 (represented by the star-like expansion pattern within L0d1c in the network - Figure 2) had a distribution that differed from the remaining L0d1c haplotypes (Additional file 2: Figure S7). Remaining LOd1c sequences, after L0d1c1 sequences were removed (L0d1c-), had a unimodal distribution and high frequencies in the GUG group. The bimodal pattern of L0d1c is therefore the result of an expansion that gave rise to the L0d1c1 subgroup and elevated frequencies of LOd1c1 in the XUN. Since the L0d1c1 sequences coalesce $\sim 2.47 \mathrm{ka}$ (SD: 1.2 kilo years), the start of expansion should be around this time (coalescence of LOd1c1 sequences occur in the large central node).

Mismatch distributions were constructed for each subhaplogroup, to further analyze the individual haplogroup histories and to test if they had notable expansions (Figure 4, Additional file 2: Figure S8 and Additional file 1: Table S3). All L0d sub-haplogroups except L0d2b, L0d2c and LOdx showed significant evidence of expansions. Subhaplogroups L0d1a and L0d2a displayed high levels of significance and their mismatch distributions showed smooth unimodal distributions with low raggedness values, indicating that a single expansion occurred at some time in the past (indicated by the $\tau$ value). The $\tau$ values of all the LOd1 haplogroups were similar, with expansions dating to $\sim 27 \mathrm{ka}$. LOd2a and L0k1 are associated with more recent expansions of $\sim 6 \mathrm{ka}$. Both the $\mathrm{M}$ and $\mathrm{R}$ haplogroups are associated with older expansions $\sim 40-50 \mathrm{ka}$, feasibly at the time when anatomically, cognitively and behaviorally modern Africans migrated to, and expanded in, Eurasia [21,22].

Caveats associated with the coalescence analysis employed in mismatch distributions are the assumption of a single, exponentially growing population and the large degrees of statistical uncertainty. Also, earlier population expansions can be obscured by recent population bottlenecks [23]. Mismatch distributions have been reported previously to have less ability to predict population expansions than neutrality test summary statistics such as Tajima's D [24], Fu's Fs [25] and the R2 statistic [26]. Diversity estimates, together with the neutrality tests for the LOd sub-haplogroups (and other haplogroups with $>10$ sequences) were also calculated and are provided in Table 3.

Neutrality tests were used to detect deviations from the assumptions of neutrality and constant population size (significantly negative Tajima D and Fs values and significantly positive R2 values indicate population growth and/or positive selection). The R2 statistic is especially powerful when sample sizes are small $(\sim 10)$, and Fs have a greater ability to detect population expansions 


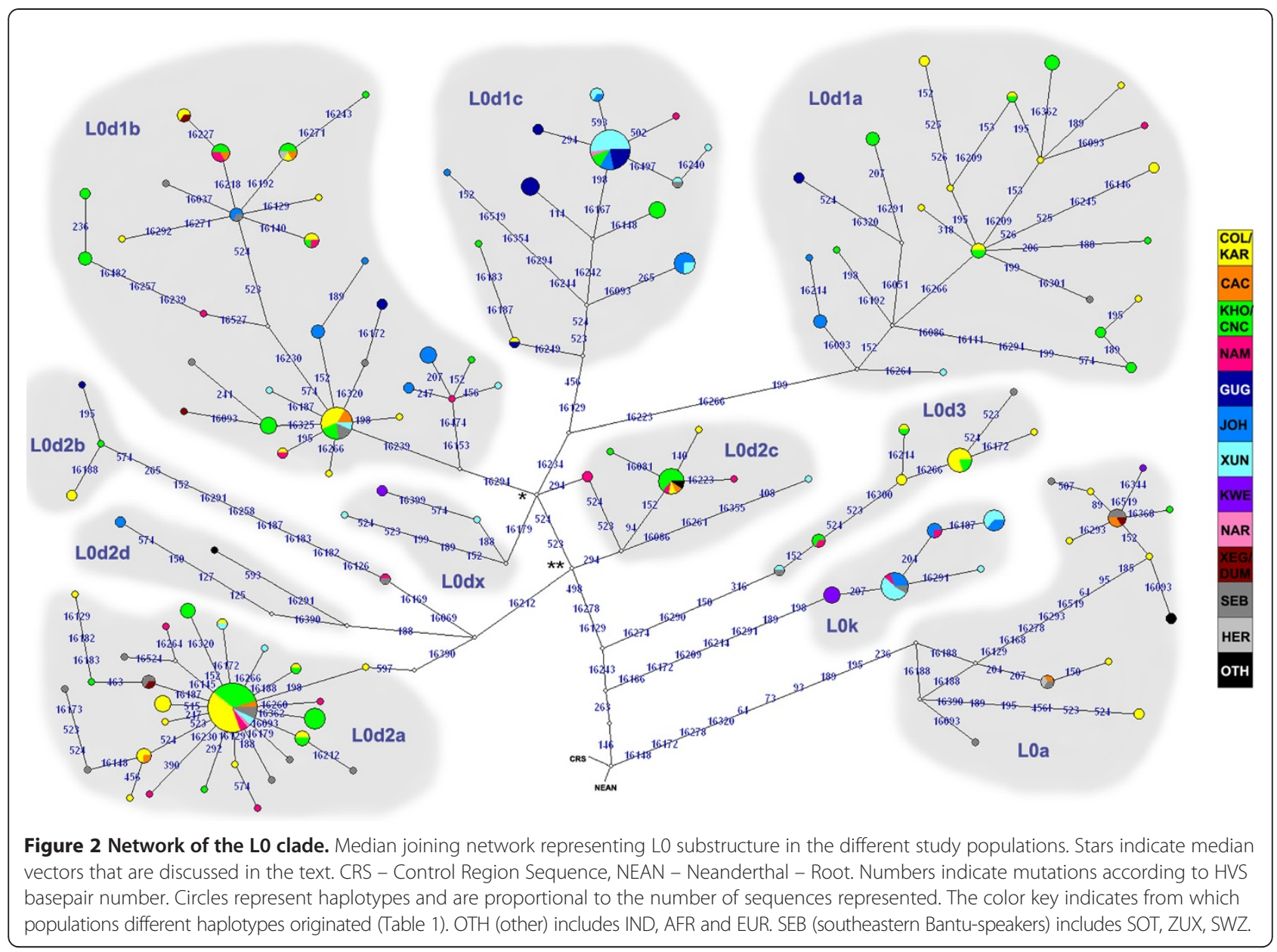

when sample sizes are large $(\sim 50)[26,27]$. Haplogroups $\mathrm{M}$ and $\mathrm{R}$, more commonly found outside of Africa, tested positive for population expansion using all three neutrality tests with highly significant p-values (Table 3 ). The LOd group as a whole had significant D and Fs values, but not for R2; the latter is a possible result of larger sample sizes [26]. Of the LOd sub-haplogroups, L0d2a had the highest significance when all three neutrality tests were used. L0d1b also attained significance in all three tests while LOd1a had a very significant Fs value, but did not reach significance in the Tajima's $D$ and R2 tests. Thus, collectively, mismatch distributions and neutrality tests unambiguously indicate a significant expansion in LOd2a and show strong support for expansions in L0d1a and LOd1b.

While neutrality tests are widely employed to test hypotheses of expansion events, recent improvements in coalescence inference methods led to increased accuracy, without the need to assume a single exponential growth curve $[28,29]$. One of these methods, Bayesian Skyline Plots (BSPs) [30], was employed to visualize the changes in $\mathrm{Ne}$ through time for each of the sub-haplogroups (Figure 4 and Additional file 2: Figure S9). It is important to note that apparent increase in Ne in a BSP could also be an indication of changes in population substructure. The L0d1a sub-haplogroup had an increase that started $\sim 25 \mathrm{ka}$ and a decrease around $\sim 5 \mathrm{ka}$. L0d1b had an increase that started at $\sim 15 \mathrm{ka}$ and another recent increase. L0d1c appears to be associated with a constant population size over an extended period followed by a transient decrease around $\sim 5 \mathrm{ka}$ which then increased rapidly in the past $1 \mathrm{ka}$. Despite a shallow coalescence time, L0d2a showed a dramatic increase from $\sim 8 \mathrm{ka}$ onwards and a further recent increase. The LOd3 BSP profile that included east African and the Kuwait haplotypes (LOd3+) (from $[10,12,31]$ as explained in the Methods section) showed a slow decline over an extended period followed by a recent increase in $\mathrm{Ne}$ (Additional file 2: Figure S9). The L0d3 profile that only included the southern African LOd3 haplotypes (LOd3) (from the current study) showed a more intense decline and an increase that started later than in the L0d3+ profile. L0k1 also showed a constant decline with a recent increase (Figure 4). The BSPs of all the LOd sub-haplogroups, except LOd1a, indicated a recent increase in $\mathrm{Ne}$ (Figure 4 and Additional file 2: Figure S9). 


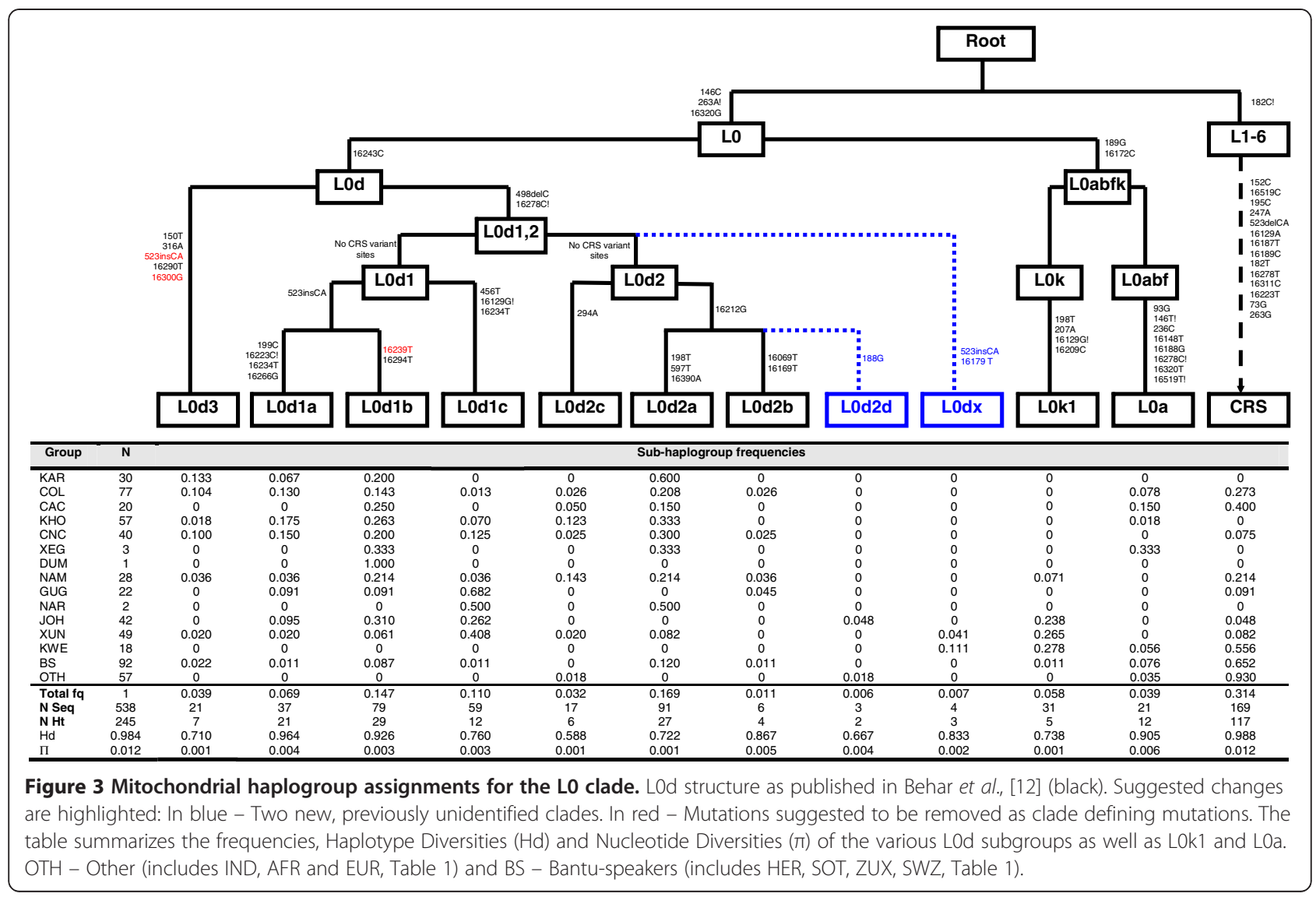

We also generated a BSP for the whole LOd haplogroup (Additional file 2: Figure S10), which shows an increase in $\mathrm{Ne}$ from $\sim 50 \mathrm{ka}$ and a more dramatic increase from $\sim 5-10 \mathrm{ka}$.

\section{Genetic affinities of Khoe, San and Coloured groups with neighboring groups}

To investigate the population group diversities and their relationship to each other and their neighbors, pairwise Fst's between the different groups were calculated (Additional file 1: Table S4) and visualized in a UPGMA tree (Figure 5A). Populations with a considerable amount of Khoe-San ancestry, inferred from the presence of LOd/k haplogroups, grouped closely together in one clade, non-African populations grouped together, Bantu-speakers and populations with large proportions of admixture from Bantu-speakers (such as CAC and KWE) grouped together, and in another clade. Furthermore, the northern Ju-speaking San groups, $\mathrm{JOH}$ and XUN, grouped together with GUG on their own, while the southern Khoe-San and selected Coloured groups (CNC and $\mathrm{KHO}, \mathrm{COL}$ and NAM, and KAR) grouped together.

To examine the evolutionary history of mtDNA haplogroups LOd/k further we removed all other mtDNA haplogroups from the groups and reanalyzed the data.
The earlier observation (Figure 5A) of the distinction between the northern San groups (GUG, JOH, XUN) and southern Coloured and Khoe-San groups (KAR, KHO, NAM, CAC, CNC, COL) was once again clearly evident (Figure 5B). Also, the CAC group now clustered within the southern San-Khoe and Coloured groups. The KWE group, however, remains an outlier.

To examine how Lok could have influenced the population affinities of the northern and southern groups, we repeated the analysis with only LOd sequences (Figure 5C). The JOH group clustered with the southern Coloured and Khoe-San groups rather than with the GUG and XUN, but was still somewhat removed from them. This is not surprising since, from the LOd haplogroup frequencies (Figure 2 and Additional file 2: Figure S3b) it is apparent that $\mathrm{JOH}$ had much lower LOd1c frequencies than GUG and XUN, but higher LOd1b frequencies (frequent in southern groups). Other southern Coloured and Khoe-San groups still grouped tightly together in a cluster and the KWE group remained an outlier (but has to be viewed with caution because it is represented by only two LOd sequences).

To examine if the genetic distances (Fst) and geographic distances $(\mathrm{km})$ between groups show any correlation within the Khoe-San-Coloured groups, the three 
Table 2 TMRCA calculated for the LOd/k subgroups and comparative whole genome estimates

\begin{tabular}{|c|c|c|c|c|c|c|}
\hline \multicolumn{7}{|c|}{ Divergeance times } \\
\hline Haplogroup & $\rho$ & $\sigma$ & Years $^{1}$ & $\mathrm{SD}^{2}$ & Years $^{3}$ & $\mathrm{Cl}$ \\
\hline LOd & 10.8580 & 2.2635 & 96601 & 20138 & 152,384 & 12,698 \\
\hline LOd1a & 7.1351 & 2.0865 & 63480 & 18563 & 34,921 & 6,349 \\
\hline LOd1b & 4.6709 & 1.5502 & 41556 & 13792 & 34,921 & 6,349 \\
\hline LOd1C & 6.7119 & 2.2906 & 59714 & 20379 & 53,175 & 7,936 \\
\hline LOd2a & 3.8242 & 1.7380 & 34023 & 15463 & 64,287 & 8,730 \\
\hline $\mathrm{LOd} 2 \mathrm{~b}$ & 8.5000 & 2.4777 & 75623 & 22044 & 64,287 & 8,730 \\
\hline $\mathrm{LOd} 2 \mathrm{C}$ & 3.2941 & 1.5519 & 29307 & 13807 & 64,287 & 8,730 \\
\hline LOd2d & 5.0000 & 1.8559 & 44484 & 16512 & - & - \\
\hline LOd3 & 8.0000 & 2.6273 & 71174 & 23375 & 100,795 & 10,317 \\
\hline LOdx & 4.0000 & 1.5411 & 35587 & 13711 & _ & _ \\
\hline LOK1 ${ }^{4}$ & 8.5161 & 2.8144 & 75766 & 25039 & 142,860 & 1,905 \\
\hline \multicolumn{7}{|c|}{ Coalescent times (TMRCA) } \\
\hline Haplogroup & $\rho$ & $\sigma$ & Years $^{1}$ & $\mathrm{SD}^{2}$ & Years $^{3}$ & $\mathrm{Cl}$ \\
\hline LOd & 9.8580 & 2.0307 & 87705 & 18067 & 100,795 & 10,317 \\
\hline LOd1 & 6.4286 & 1.2576 & 57194 & 11189 & 53,175 & 7,936 \\
\hline LOd2 & 4.8718 & 1.6199 & 43343 & 14412 & 64,287 & 8,730 \\
\hline LOd1a & 4.1351 & 1.1634 & 36789 & 10351 & 18,254 & 6,349 \\
\hline L0d1b & $3.0 / 09$ & 1.1845 & 32659 & 10538 & 16,667 & 6,349 \\
\hline LOd1C & 4.7119 & 1.8019 & 41921 & 16031 & 23,810 & 5,555 \\
\hline LOd2a & 1.8242 & 1.0143 & 16230 & 9024 & 8,730 & 3, \\
\hline LOd2b & 6.5000 & 2.0344 & 57829 & 18100 & - & - \\
\hline $\mathrm{LOd} 2 \mathrm{C}$ & 2.2941 & 1.1867 & 20410 & 10558 & 20,635 & 5,555 \\
\hline LOd2d & 4.0000 & 1.5635 & 35587 & 13910 & - & - \\
\hline LOd3 & 4.0000 & 1.7037 & 35587 & 15157 & 31,746 & 7,936 \\
\hline LOdx & 3.0000 & 1.1726 & 26690 & 10432 & - & 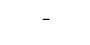 \\
\hline LOK1 ${ }^{4}$ & 1.5161 & 0.9596 & 13488 & 8538 & 39,683 & 8,730 \\
\hline
\end{tabular}

Years are calculated using $\rho$ [20] and multiplying with the mutation rate from Ward et al., [18].

${ }^{2}$ Standard deviation (SD) are calculated from $\sigma$ by multiplying with the specific mutation rate from Ward et al., [18].

${ }^{3}$ Estimates based on whole mitochondrial genomes obtained from Behar et al., [12].

${ }^{4}$ LOk estimates from present study only include L0k1, while the Behar et al., study include L0k1 and LOk2 haplotypes.

pairwise Fst matrices were correlated with a geographic distance matrix (the KWE, Bantu-speakers and nonAfricans were excluded for all three correlations). All three straight lines fitted to a graph of geographic distance vs. genetic distance, had significant positive slopes (Figure 5D-F). When non-LOd/k sequences were removed (Figure 5E), the slope was steeper compared to when all sequences were included (Figure 5D), and even steeper for LOd sequences only (Figure 5C). Mantel tests also confirmed the relationship between the genetic and geographic distances. For the correlation involving all sequences the correlation coefficient ( $r$ ) was $0.402750(\mathrm{p}=0.027)$, for L0d $/ \mathrm{k}$ sequences, $\mathrm{r}=0.449854$ $(\mathrm{p}=0.034)$ and for L0d sequences only, $\mathrm{r}=0.439081$ $(\mathrm{p}=0.033)$. Both Mantel tests and linear regressions thus confirmed a positive relationship between geographic distance between groups and genetic distance. Maternal lineage-based population structure within Khoe-San groups is thus, at least in part, explained by geographic distance between the different groups. Furthermore, unequal amounts of admixture from Bantu-speakers and non-Africans into the various Khoe-San groups does not account for the observed pattern, instead admixture from these groups abated the relationship.

\section{Discussion}

Two levels of mtDNA analysis, the first involving phylogeography, and the second population history, allowed us to evaluate how females have contributed in shaping the mtDNA pool of southern African Khoe-San and some Coloured populations. Like other studies before this $[9,10,15,17,31,32]$, the high frequencies of haplogroup LOd among the Khoe, San and Coloured populations was found at varying frequencies in the groups we examined (Figure 1). Variation within LOd/k sub-haplogroups was found to be population specific and also showed differences in their geographic distributions (Figure 3). Using a combination of computational analysis and statistical tests we were able to evaluate the demographic histories of Khoe and San groups prior to, and after, contact with other groups in southern Africa. The genetic data, albeit only mtDNA, was used in conjunction with historical, linguistic, ethnographic and archaeological data, to better understand the prehistory of the Khoe and San.

It is generally accepted that southern Africa was occupied exclusively by Khoe and San people prior to the migration of Bantu-speakers to the region at $\sim 2 \mathrm{ka}$ [33]. From $\sim 170 \mathrm{ka}$ onwards the archaeological records at sites such as Pinnacle Point 13B [34], Blombos [35], Sibudu [36] and Border Cave [37], in southern Africa provide evidence for the presence of humans who started to think and behave in more complex ways than before. It is likely that the people associated with these cultural artifacts were ancestors of the present day Khoe and San; whether this assumption is true could potentially be resolved in future with ancient DNA studies. However, direct evidence of San-like hunter-gatherer cultural material in southern Africa has been reported as far back as $40 \mathrm{ka}$ [37], and autosomal DNA studies have shown that Khoe-San populations diverged from other human populations $>100 \mathrm{ka}$ [38-40].

\section{Notes on LOk and LOd topology}

While many sequences (31) belonged to haplogroup L0k, they were represented by only five different haplotypes, 
Lod1a
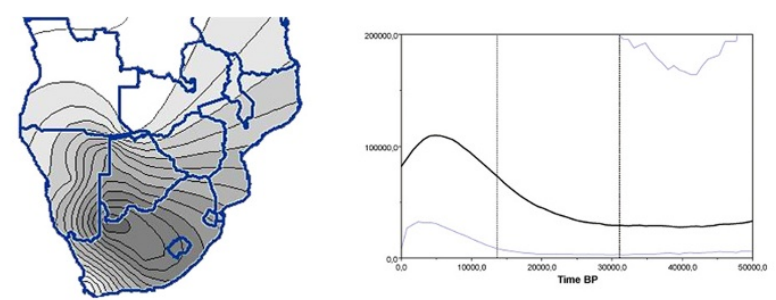

Lod1b

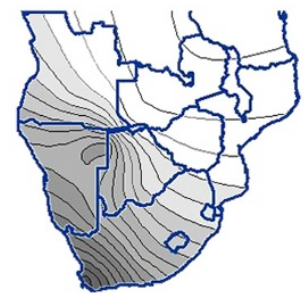

Lod1c
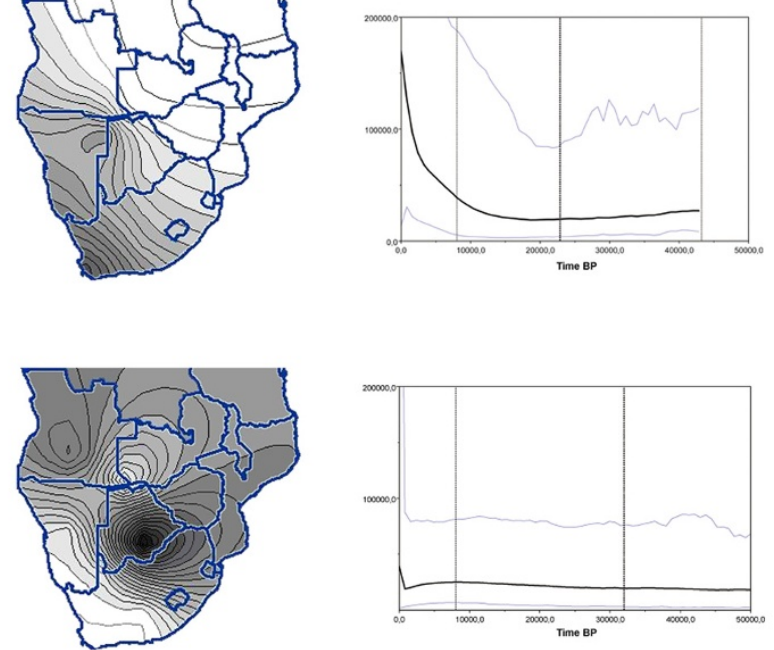

Lod2a
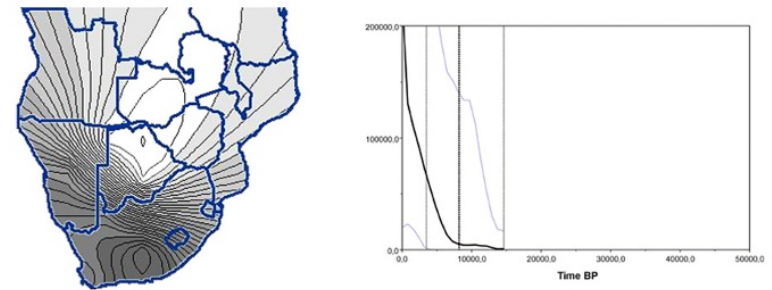

Lod3


L0k1

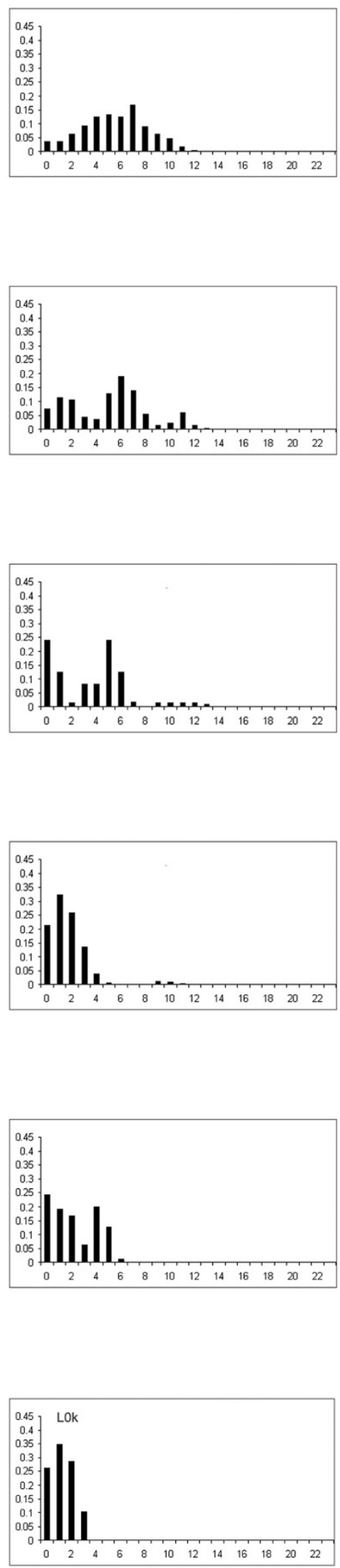

Figure 4 (See legend on next page.) 
(See figure on previous page.)

Figure 4 Contour plots, Bayesian Skyline Plots and mismatch distributions of LOd/k haplogroups. First Column: Contour plots indicating the frequency distributions of $\mathrm{LOd} / \mathrm{k}$ subgroups. Color range is from 0 (white) to $>60 \%$ (black) in increasing shades of gray. Second Column: Bayesian Skyline plots of haplogroups showing changes in $N_{e}$ through time. $N_{e}$ is represented on the $Y$-axis, while years ago are represented on the X-axis, with the present indicated by 0. LOd3 includes only LOd3 sequences from the present study (see Additional file 2: Figure S9 for inclusion of east African and Kuwait sequences). Black bold vertical lines indicate the coalescence date and the lighter vertical lines the $95 \%$ confidence intervals for the coalescence. Blue lines indicate the $95 \%$ confidence intervals for BSP lines (black). Third Column: Mismatch distributions of LOd/k sub-haplogroups.

all belonging to L0k1. L0k has two sub-haplogroups L0k1 and L0k2, that separated at $\sim 40 \mathrm{ka}[12]$. As yet, there has been only one report of L0k2 in an individual from Yemen [12], while L0k1 was found exclusively in the San groups [9-12]. The L0k1 haplotypes of the current study coalesced by $13 \mathrm{ka}$ and diverged from other sequences in $\mathrm{L} 0$ at $75 \mathrm{ka}$ (Table 2).

Altogether, 317 sequences were resolved into haplogroup L0d (111 unique haplotypes). Haplotypes were grouped into the seven sub-haplogroups according to Behar et al., [12] and two extra previously unidentified sub-haplogroups (Figure 3). The LOd haplogroup was estimated to have a coalescence time of $87 \mathrm{ka}(+/-18)$ and diverged from the other L0 groups by $96 \mathrm{ka}(+/-20)$ (Table 2), a shallow time compared to whole genome studies [12].

Previously, LOd3 have been identified as the oldest LOd clade [12], and it also occurred as the earliest LOd branch on our tree and network (Figure 2 and Additional file 2:
Figure S3b). The divergence from the other LOd sequences dated to $71 \mathrm{ka}(+/-23)$ and L0d3 sequences coalesced at $35 \mathrm{ka}(+/-15)$ (Table 3). Only two L0d3 sequences formed part of the whole genome study [12], one from a San individual and one from an individual from Kuwait (coalescence $\sim 31 \mathrm{ka}$ ) and seven cladedefining mutations were identified [12]. In the present study, LOd3 is represented by seven haplotypes and based on data displayed in the network (Figure 2), it is suggested that $16300 \mathrm{G}$ and 523delCA should be removed as clade defining mutations for L0d3 since earlier sequences in our network did not contain these mutations (Figure 2 and Figure 3).

Gonder et al. [31], did whole genome studies on a wide range of African sequences including the Platfontein !Xun and Khwe and the Sandawe from Tanzania. The !Xun/Khwe and Sandawe from that study were the only groups that contained LOd sequences (Table 1). When LOd sequences [31] were classified

Table 3 Diversity statistics and neutrality tests of LOd/k subgroups and comparative haplogroups

\begin{tabular}{|c|c|c|c|c|c|c|c|c|c|c|c|c|c|}
\hline Group & $\mathrm{N}$ seq & N Ht & $\mathrm{Hd}$ & $\pi$ & $\theta_{\mathrm{S}}$ & $\mathrm{W}-\theta_{\mathrm{S}}$ & $\mathrm{Ne}$ & Tajima's D & Tajima's D p-value & Fs & Fs p-value & R2 & R2 p-value \\
\hline LOd & 317 & 111 & 0.962 & 0.00732 & 0,01419 & 15.342 & 2730 & -1.45547 & $0.028^{*}$ & -33.984 & $<0.001^{* * *}$ & 0.0421 & 0.069 \\
\hline LOd1a & 37 & 21 & 0.964 & 0.00436 & 0.00584 & 6.468 & 1151 & -0.84168 & 0.210 & -8.871 & $0.001^{* *}$ & 0.0849 & 0.120 \\
\hline Lod1b & 79 & 29 & 0.926 & 0.00279 & 0.00551 & 6.072 & 1081 & -1.51856 & $0.040^{*}$ & -17.250 & $<0.001^{* * *}$ & 0.0488 & $0.040^{*}$ \\
\hline LOd1c & 59 & 12 & 0.760 & 0.00248 & 0.00388 & 4.305 & 766 & -1.09831 & 0.136 & -1.628 & 0.273 & 0.0714 & 0.186 \\
\hline LOd2a & 91 & 27 & 0.722 & 0.00110 & 0.00463 & 5.116 & 910 & -2.29659 & $<0.001^{* * *}$ & -23.082 & $<0.001^{* * *}$ & 0.0240 & $0.005^{* *}$ \\
\hline LOd2b & 6 & 4 & 0.867 & 0.00458 & 0.00393 & 4.380 & 779 & 1.03370 & 0.864 & 1.229 & 0.701 & 0.2429 & 0.738 \\
\hline $\mathrm{LOd} 2 \mathrm{C}$ & 17 & 6 & 0.588 & 0.00129 & 0.00239 & 2.662 & 474 & -1.65319 & $0.032^{*}$ & -1.475 & 0.134 & 0.1135 & 0.128 \\
\hline LOd2d & 3 & 2 & 0.667 & 0.00357 & 0.00359 & 4.000 & 712 & na & na & na & na & na & na \\
\hline LOd3 & 21 & 7 & 0.710 & 0.00121 & 0.00124 & 1.390 & 247 & -0.08107 & 0.511 & -1.287 & 0.170 & 0.1327 & 0.432 \\
\hline $\operatorname{LOdx}$ & 4 & 3 & 0.833 & 0.00238 & 0.00244 & 2.727 & 485 & na & na & na & na & na & na \\
\hline LOk1 & 31 & 5 & 0.738 & 0.00110 & 0.00089 & 1.001 & 178 & 0.58176 & 0.742 & -0.044 & 0.518 & 0.1522 & 0.721 \\
\hline LOa & 21 & 12 & 0.905 & 0.00590 & 0.00526 & 5.837 & 1039 & 0.30935 & 0.676 & -1.317 & 0.290 & 0.1475 & 0.725 \\
\hline $\mathrm{L} 2 \mathrm{a}$ & 29 & 10 & 0.852 & 0.00332 & 0.00367 & 4.074 & 725 & -0.29380 & 0.430 & -0.739 & 0.382 & 0.1153 & 0.472 \\
\hline L3d & 20 & 6 & 0.558 & 0.00281 & 0.00253 & 2.819 & 502 & 0.41429 & 0.700 & 2.092 & 0.849 & 0.1506 & 0.662 \\
\hline L3e & 22 & 16 & 0.957 & 0.00575 & 0.00545 & 6.035 & 1074 & 0.08399 & 0.601 & -5.350 & 0.056 & 0.1345 & 0.611 \\
\hline$M$ & 19 & 18 & 0.994 & 0.00620 & 0.01340 & 14.592 & 2596 & -2.17227 & $0.004^{* *}$ & -11.280 & $<0.001^{* * *}$ & 0.0462 & $<0.001^{* * *}$ \\
\hline $\mathrm{R}$ & 38 & 35 & 0.994 & 0.00793 & 0.01702 & 19.326 & 3439 & -1.93058 & $0.010^{* *}$ & -27.889 & $<0.001^{* * *}$ & 0.0466 & $<0.001^{* * *}$ \\
\hline
\end{tabular}

* $\mathrm{p}$-value $<0.05$.

** p-value $<0.005$

*** $p$-value $<0.001$. 


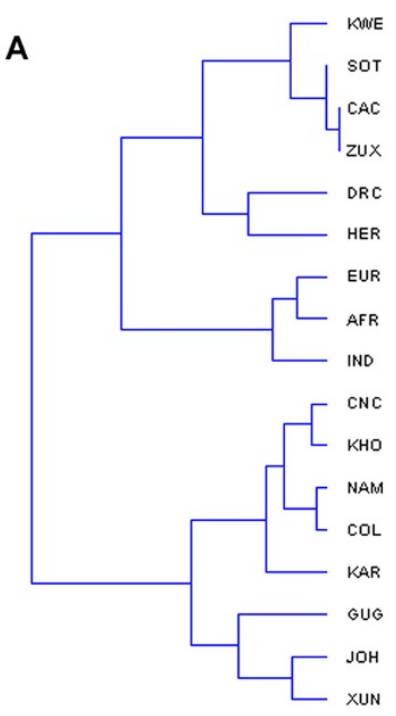

D

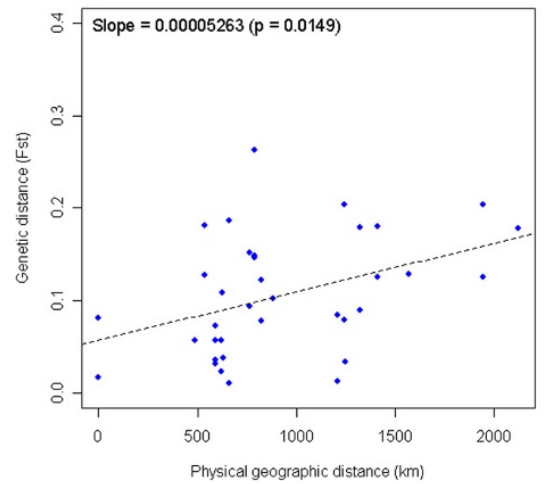

B

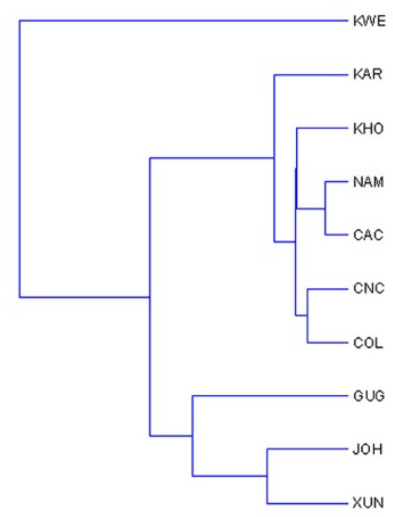

C

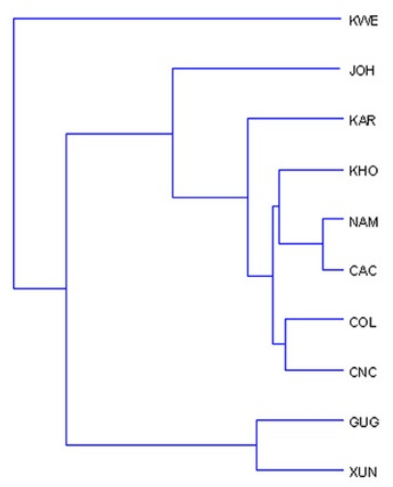

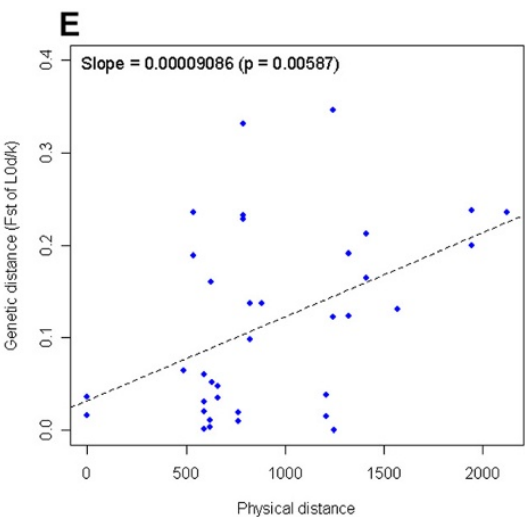

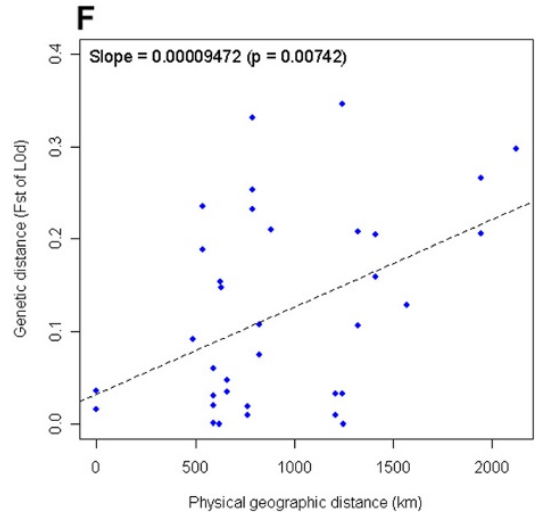

Figure 5 Trees based on Fst and correlation of genetic distance with geographic distance between sample groups. Trees representing mtDNA Fst values between different populations in the study group for $\mathbf{A}$ : all mtDNA sequences $\mathbf{B}$ : LOd/k sequences and $\mathbf{C}$ : LOd sequences. D-F: Pairwise comparisons between geographic distance (X-axis) and mtDNA Fst genetic distance (Y-axis), corresponding to trees in $\mathbf{A}$-C.

according to the nomenclature of [12], all the !Xun/Khwe LOd sequences were resolved into LOd1 or LOd2 (Table 1), while all the Sandawe LOd sequences fell into LOd3. When the LOd3 sequences from [31] and [12] were analyzed in a network, together with the LOd3 sequences from the present study, two separate groups formed; a Tanzania/Kuwait L0d3 group and a southern Africa L0d3 group (Additional file 2: Figure S11). It is suggested here that the Tanzanian/Kuwait sequences should be classified as an L0d3 sub-haplogroup, L0d3a, defined by the 16129 G-A, 16274 A-G! (reversion) and 16399 A-G mutations. The closest related haplotype in the southern Africa branch of LOd3 to the Tanzania/Kuwait branch occurred in the Karretjie People and Coloured groups from Colesberg. A haplotype found in the Karretjie People and Coloured groups was directly ancestral to the L0d3a branch (Additional file 2: Figure S11).

With the inclusion of the east African haplotypes, the whole LOd3 clade diverged from other LOd sequen- ces $\sim 83 \mathrm{ka}$, while all the L0d3 sequences coalesced at $\sim 47 \mathrm{ka}$. The divergence of the L0d3a sub-haplogroup from the southern Africa haplotypes was dated at $41 \mathrm{ka}$. LOd3a sequences coalesced at $\sim 28 \mathrm{ka}$.

The L0d1,2 branch was separated from their ancestral node by two mutations, 498delC and a back-mutation, 16278C! (Figures 2 and 3). No HVS mutations differentiate between LOd1 and LOd2 (Figure 3). They are, however, defined by 5 and 6 coding region mutations, respectively [12]. When analyzing only the HVS, the branch separating LOd1 from LOd2, collapses. This can be seen in the network where all subgroups met at two central nodes (marked with * and $*$ in Figure 2). The absence of the 523insCA mutation (seen as an L0d1aLOd1b defining mutation in Figure 3) separated the L0d2 sequences from the LOd1 sequences in the network.

The haplotype diversity for L0d1a (0.96) was the highest of all the LOd sub-haplogroups in the study (37 HVS sequences that included 21 haplotypes) (Figure 3). 
The 21 haplotypes converged by $\sim 37 \mathrm{ka}$ (Table 3 and Additional file 2: Figure S5), much older than the three L0d1a sequences in the whole genome study (at $\sim 18 \mathrm{ka}[12]$ ).

The LOd1b clade was previously further defined by the $16239 \mathrm{~T}$ and 16294 T HVS changes (Figure 3) [12], however, a large subset of sequences from the present study, did not contain the 16239 mutation (Figure 2). It appears that 16239 should not be used as a clade defining mutation for L0d1b (Figure 3), but this will have to be assessed with whole genome sequencing. The coalescence times of the 29 HVS haplotypes from the present study and the four haplotypes employed in the whole genome study [12] were similar (Table 2).

The L0d1c haplogroup contained 59 LOd1c HVS sequences described by 12 unique haplotypes. The 12 haplotypes coalesced by $\sim 42 \mathrm{ka}$ and separated from L0d1a/b by $\sim 60 \mathrm{ka}$ (Table 2 and Additional file 2: Figure S5).

L0d2a was defined on the network by $597 \mathrm{~T}$ and 16390A (Figure 2). Previously, $198 \mathrm{~T}$ was also suggested as an L0d2a defining mutation [12], however, one of our LOd2a sequences did not contain the mutation. The 27 LOd2a HVS haplotypes of the present study had a TMRCA of $\sim 16 \mathrm{ka}$ (Table 3), coalescence analysis (applied in the BSP - Figure 4), however, dated the coalescence of L0d2a at $\sim 8 \mathrm{ka}$, which is closer to the whole genome study estimate of $\sim 9$ ka [12] (Table 2).

The defining mutations of L0d2b were $16069 \mathrm{~T}$ and $16169 \mathrm{~T}$. Four of the six sequences in L0d2b were separated by a very long branch ( 9 mutations) from the other two sequences and the LOd2b node had high coalescence and divergence times, higher than LOd3, which is inconsistent with previous classifications [12]. Three mutations on the long branch are highly reoccurring mutations and might decrease coalescence times if their weights are decreased, however, it remains highly likely that terminal nodes in this group were grouped incorrectly with other L0d1b haplotypes through network analysis. Although the terminal branches contain the L0d2b defining mutations, 16212, 16069 and 16169, whole genome sequences are necessary to establish whether they perhaps represent another LOd subhaplogroup (Table 2 and Additional file 2: Figure S5). In the whole genome study [12], the one representative L0d1b sample, only contained the 16212, 16069 and 16169 mutations and not the additional mutations that defined the three terminal groups in the LOd2b clade on the network.

Three subgroups within LOd2 were previously identified; LOd2a, LOd2b and LOd2c [12]. The present study had representation across these three L0d2 haplogroups and also identified a fourth group; henceforth called LOd2d (Figure 3). LOd2d grouped with LOd2a/b and all three these groups were defined by the 16212 G mutation, while L0d2d was further defined by 188A-G (a reoccurring mutation), with an absence of the clade-defining mutations of LOd2a and LOd2b. Thus although LOd2d is suggested here as a new sub-haplogroup of L0d2, its position needs to be confirmed by whole genome sequencing.

The LOd2c sub-haplogroup consisted of 17 sequences (6 haplotypes), with a coalescence age of $\sim 20$ ka and divergence from L0d2abd at $\sim 29 \mathrm{ka}$, the whole genome study had an older divergence date ( 64 ka) [12] (Table 2 and Additional file 2: Figure S5). Only few HVS defining mutations for LOd2c exist (only 294a distinguishes the LOd2c from the LOd1,2 core haplotype), while several coding region mutations separate LOd2c from LOd2ab [12], which explains the differences in divergence times.

LOdx is the second new sub-haplogroup suggested in this paper, its exact position on the tree and network can only be affirmed through whole genome sequencing. It appears to be an LOd1 sub-group due to the presence of the 523insCA mutation; however, due to the instability of this length repeat mutation, we assigned the preliminary designation LOdx. The sub-haplogroup was further defined by the $16179 \mathrm{~T}$ mutation.

\section{Evolutionary history of mtDNA haplotypes in haplogroups LOd/k}

All of the Khoe-San and sampled Coloured groups, with the exception of the Khwe, harbored LOd as the commonest haplogroup (Figure 1). LOd frequencies in the !Xun (65\%) and the Khwe (11\%) were similar to previously reported frequencies (Additional file 1: Table S1 and Additional file 2: Figure S4). If we assume LOd was the predominant Khoe-San associated haplogroup in the past, the BSP representation of change of $\mathrm{Ne}$ through time for the whole LOd clade can be seen as a representation of the population size change of all southern African Khoe-San predecessor population groups from $\sim 100 \mathrm{ka}$ till present (Additional file 2: Figure S10). Overall it appears if $\mathrm{Ne}$ of southern African Khoe-San groups increased from $\sim 50-60 \mathrm{ka}$ and even more so during the last $10 \mathrm{ka}$ of the Holocene. Contextually, the first increase occurs during the later phases of the Middle Stone Age (MSA) and marine isotope stage (MIS) 3, and the second increase with the early Holocene or MIS 1 [41], both MIS 3 and 1 are considered phases of climate improvement after the cooler conditions often generalized for of MIS 4 and 2.

LOd sequences coalesce in the MSA phase informally known as the pre-Still Bay and would also include the Mossel Bay technocomplex [41,42]. They immediately precede a period of behavioral and cognitive florescence, linked with early evidence of modern or complex human behavior and cognition, expressed through material culture associated with the well-known Still Bay 
and Howiesons Poort technocomplexes [41,43,44]. In fact, finds indicating symbolically mediated behavior such as engraved ochre pieces and an ochre-processing workshop at $\sim 100 \mathrm{ka}[35,45,46]$ would seem to coincide with the coalescence of LOd haplogroups [12].

It appears that the subsequent expansion at $\sim 50 \mathrm{ka}$ gave rise to all the L0d1,2 sub-haplogroups (also see Additional file 2: Figure S5). Almost all the L0d1,2 sub haplogroups diverged roughly between $60 \mathrm{ka}$ and $40 \mathrm{ka}$ (Additional file 2: Figure S5). This was also the timeframe for the initial expansion of the LOd group as a whole (Additional file 2: Figure S10), and the various LOd1 and L0d2 subgroups could be seen as remnants of this expansion phase. This phase marks the early stages of the warmer MIS 3 and the end of the Howiesons Poort technocomplex at $\sim 58 \mathrm{ka}$. Based on certain aspects of the archaeological record it is sometimes argued that so-called modern human behavior was 'lost' before becoming firmly established at $\sim 40 \mathrm{ka}$, yet several lines of evidence, as well as theoretical reasoning, question this likelihood [41,47]. The period from $\sim 58 \mathrm{ka}$ to $\sim 45 \mathrm{ka}$ is known as the post-Howiesons Poort or Sibudu technocomplex [41,48], and at the name site in KwaZulu-Natal (South Africa) human behavior was clearly different, but no less complex than during the preceding Howiesons Poort and Still Bay phases $[36,49,50]$. Some of the behavioural trends, could indicate social and behavioural plasticity and complexity, and are not dissimilar to those observed among recent hunter-gatherers [51].

Subsequently, the LOd1 sub-haplogroups (especially L0d1a, L0d1b) showed signs of expansion during the transition of MSA to Later Stone Age (LSA). The final MSA ( 20-40 ka) and the early LSA ( 18-40 ka) phases overlap because of variability in stone tool assemblages and research to clarify this complicated transitional period is ongoing; at sites where all the archaeological phases are represented, we do not see dramatic breaks, but rather a gradual abandonment of MSA technologies in favor of transitional tool-making traditions culminating into LSA assemblages as a result of localized behavioral change and adaptation [42,51-53]. Thus far, the earliest art in southern Africa that can be associated with a shamanistic worldview was recorded at Apollo 11 in Namibia dated to $\sim 30 \mathrm{ka}$ [54]. This indicates that by this time people already had belief systems similar to those recorded for recent hunter-gatherers in the region [55]. The two haplogroups with a current southern distribution, L0d1a and L0d1b, had much stronger expansion signals during this transitional stage than the LOd1c haplogroup, which are currently associated with northern San groups. L0d1a had a growth signal that precedes the LOd1b growth phase by at least $10 \mathrm{ka}$. It was difficult to judge the start of expansion in LOd2a because of the shallow coalescence time of haplotypes. It might be that the LOd2a growth started in the same timeframe as LOd1b. LOd2a and LOd1b was the main groups in the southern populations and might share similar histories. The growth curve in L0d2a was, however, much steeper than in LOd1b.

L0d1a had a central distribution with the highest frequencies in the regions occupied by the $\neq$ Khomani (Figure 3, Additional file 2: Figures S4 and S6). This haplogroup had low frequencies in most of the populations $(<20 \%)$, but was geographically widespread and present in most groups (Figure 3 and Additional file 2: Figure S4). The BSP of L0d1a (Figure 4), showed a clear indication of an expansion that started between $25 \mathrm{ka}$ and $30 \mathrm{ka}$, as well as a recent decline in population size from 3-4 ka to the present. The LOd1a network (Figure 2) showed a star-like expansion pattern associated with the southern groups. The central haplotype of the pattern was small and derivative sequences accumulated several mutations. This pattern is indicative of an older expansion in which the central haplotype declined over time and derivative haplotypes accumulated mutations. A mismatch distribution of LOd1a showed a smooth unimodal distribution with a low raggedness index suggesting a single expansion of the haplogroup by $\sim 28 \mathrm{ka}$, as indicated by the $\tau$ value (Figure 4 and Additional file 1: Table S3). Of the three neutrality tests employed, only the Fs test showed a significant indication of an expansion (Table 3). The Fs statistic, however, is used widely and several studies showed it to be an accurate indicator of expansions $[26,56]$.

The BSP of L0d1a furthermore showed a recent decline that started at $\sim 4 \mathrm{ka}$, coinciding with the end of the Wilton technocomplex that started at $\sim 8 \mathrm{ka}$, and is often considered a 'classic' LSA expression of complex, modern hunter-gatherer societies [57]. Archaeological site frequency can only be considered to vaguely reflect fluctuation in population sizes because of sampling bias. None the less, the archaeological record for southern Africa seems to indicate an increase in sites (and perhaps the general population size) during the last $4 \mathrm{ka}$. This increase was more prominent from $\sim 2$ ka onwards when herding was introduced to the region [33,58]. Reasons for the decline in L0d1a might be that groups carrying the LOd1a haplogroup in high frequencies were out-competed and displaced by other groups that expanded during this stage. It could be that L0d1a was the predominant group in hunter-gatherers who were displaced by pastoralist groups and/or lifeways. The latter might represent groups moving in from other areas, or drift effects of other haplogroups increasing within the same population. If hunter-gatherer groups in the past lived as small isolated metapopulations with limited amounts of gene-flow between them, the influence of 
genetic drift might have been more pronounced than in population groups with more gene-flow between groups [59].

L0d1b had a distribution that is concentrated in the south and declined towards the north (Figure 4). The Cape Coloured group had LOd1b as their most prevalent LOd haplogroup, while in the other southern groups it was the second most prevalent (Figure 3 and Additional file 2: Figure S4). Interestingly, it was also the most prevalent group in the Ju/'hoansi while frequencies in the other northern groups were lower (Figure 3 and Additional file 2: Figure S4). Published studies also found LOd1b to be the predominant haplogroup in the $\mathrm{Ju} /$ 'hoansi [11] while occurring at low frequencies in the !Xun [9] (Additional file 1: Table S1).

The expansion dates for LOd1b indicated by the BSP are $\sim 15 \mathrm{ka}$ and $3 \mathrm{ka}$. Based on archaeological site frequency, the population density of the southern parts of South Africa, seems to have increased markedly from $\sim 12 \mathrm{ka}$ and particularly during the last $4 \mathrm{ka}[33,58]$. The expansion patterns seen for L0d1b thus loosely resemble the age estimates and increases in the archaeological sequence and site frequencies (Figure 4). The network also showed several star-like expansion patterns indicating that the haplogroup went through more than one phase of population growth (Figure 2), and the mismatch distribution indicated more than one expansion (a recent and an older expansion) (Figure 4). Additionally, all three neutrality tests significantly supported statistics that indicated expansion (Table 3).

L0d1c was completely absent or present at very low frequencies in the southern groups (Figure 4). It increased northwards, where it is the predominant LOd group (except in the Ju/'hoansi) (Figure 3 and Additional file 2: Figure S4). In published results, LOd1c was also the predominant group in the !Xun [9] and were undetected in the Ju/'hoansi [11] (Additional file 1: Table S1, Additional file 2: Figure S4).

A sub-clade of LOd1c, LOd1c1 was previously defined [12] and in our study most LOd1c sequences belonged to LOd1c1 (but only 6 of the 12 haplotypes) (Figure 3). L0d1c1 is represented by a large star-like pattern at the tip of the LOd1c network, which indicated a recent expansion (Figure 2). When the contour plot of LOd1c was split between the early L0d1c haplotypes and the L0d1c1 haplotypes, it was apparent that the early L0d1c haplotypes had their highest frequencies in the central /Gui+//Gana+Kgalagari group, but is almost absent in the !Xun (Additional file 2: Figure S7). L0d1c1 haplotypes, however, had their highest frequency in the !Xun. It therefore seems the LOd1c1 expansion is associated with the !Xun.

The low L0d1c frequency in the Ju/'hoansi was surprising given that they are geographically located between the !Xun and the /Gui+//Gana. The Ju/'hoansi and !Xun socio-economies, however, are vastly different; while the $\mathrm{Ju} /$ 'hoansi continued to live as foragers, the !Xun adopted crop cultivation and herding from the local Ovambo population, with whom they have lived in close association for centuries $[3,60]$. This change in the !Xun lifeway could explain why the BSP for L0d1c show a decline of $\mathrm{Ne}$ concurrent with the introduction of pastoralism to their area, but then started to increase rapidly by $1 \mathrm{ka}$ (Figure 4).

The L0d1c BSP plot (Figure 4) showed a slight increase in population size throughout the LSA from $\sim 25 \mathrm{ka}$ until $\sim 5 \mathrm{ka}$. This increase, however, was not comparable to the dramatic increase seen in L0d1a and LOd1b as seen in the Model (SSD) p-value of the mismatch distribution (Additional file 1: Table S3) and BSPs (Figure 4). Furthermore all three neutrality tests rejected the expansion hypothesis (Table 3).

The L0d2a haplogroup had a distribution concentrated in the south (Figure 4), and it was the most prevalent LOd group in all the southern groups, except the Cape Coloured where it was the second most prevalent. All the southern groups had either LOd2a or LOd1b as their most prevalent and second most prevalent groups (Figure 3 and Additional file 2: Figure S4). LOd2a was absent in most northern groups and at low frequencies in the !Xun. LOd2a was the LOd group that had the highest incorporation into the Bantu-speaking groups (Figure 3 and Additional file 2: Figure S4).

L0d2a formed a large star-like expansion pattern that is indicative of a massive recent expansion in the population groups represented in the haplogroup (Figure 2). All three neutrality tests detected an expansion in LOd2a with the highest associated significance of all the LOd/k subgroups (Table 3). The mismatch distribution did not reject an expansion hypothesis and the mismatch graph shows a smooth unimodal curve that indicated a recent expansion (Figure 4 and Additional file 1: Table S3). The $\tau$ value dated the expansion to $\sim 7 \mathrm{ka}$ (Additional file 1: Table S3). Looking at the BSP (Figure 4) one can see an immediate dramatic increase in $\mathrm{LOd} 2 \mathrm{a} N e$ from the coalescence date $(\sim 8 \mathrm{ka})$ onwards until present. A further, recent expansion (at $\sim 1 \mathrm{ka}$ ) was also evident. In the span of $8 \mathrm{ka}$ the $\mathrm{Ne}$ increased $>20$ times (Figure 4), these data are consistent with apparent increases in archaeological site frequencies in South Africa and Lesotho [41]. The coalescence age can be archaeologically linked to the start of the Wilton technocomplex that is widely distributed across the South African-Lesotho landscape [41] and represents a microlithic industry.

Most haplogroups show abrupt increases in population sizes around the time of the introduction of pastoralism (Figure 4 and Additional file 2: Figure S9). This could be due to population increases coupled to the adoption of 
pastoralist practices or population increases due to indirect benefits gained from surrounding pastoralist groups. Alternatively (or additionally), the increases in the BSPs can be an indication of changes in population substructure during these times, which could be expected with the drastic social changes linked to a shift in subsistence practices. While LOd2a had a more recent expansion phase that correlated with the introduction of pastoralism, the major part of the LOd2a expansion phase predated the introduction of sheep and/or goats into the southern regions. This rapid increase might be part of the increase noted in the archaeological record that occurred from $\sim 12$ ka onwards. This was, however, before the coalescence time indicated on the BSP (Figure 4). From archaeological and paleo-environmental studies we know that the period between $10 \mathrm{ka}$ and $5 \mathrm{ka}$ is associated with the reach of maximum temperatures after the Last Glacial Maximum (LGM) and the completion of the rise in sea levels. It might be that these events concentrated populations and increased social networking, which led to the spread of technologies between groups in the south. Perhaps inducing development of microlithic technocomplexes such as the Wilton technocomplex. Further expansions into new habitats and elaboration of material culture and technology, are noted in the archaeological record from $\sim 4$ ka onwards [41].

In contrast to the above-mentioned haplogroups, LOd3, showed no evidence of expansions associated with the LSA to MSA transition, yet, it also had southern distribution. Drift effects could cause this haplogroup to decrease while other haplogroups in the same populations increased. Another explanation could be that this haplotype was not subjected to similar conditions as the other LOd haplotypes during the early and middle LSA and thus might have only been introduced to these territories subsequent to these phases. During the last 4-2 ka, however, the expansion phases of the LOd3 haplogroup correlates with the introduction of pastoralism in eastern and southern Africa respectively, so that we suggest that the populations that carried it either adopted or benefited from herding.

L0d3 was present in the southern Khoe-San and Coloured groups but almost absent in the northern groups (only one !Xun individual was assigned to LOd3) (Figure 3 and Additional file 2: Figure S4). Although L0d3 had low frequencies compared to the other LOd subgroups, in all the southern groups, its distribution showed a south-north cline. When results from three previous studies $[9,10,31]$ are combined with the present study, a group of 225 !Xun, Khwe and Ju/'hoansi were screened and only one !Xun individual (from the present study) contained an LOd3 sequence. This indicates an extremely low incidence of LOd3 in the northern San groups.
Tishkoff et al., discussed the possibility that the linguistic connection between the Sandawe and KalahariKhoe languages [7] was associated with the LOd genetic connection [10]. They concluded that the maternal genetic connection between the two groups was very deep (>15 ka) and it was unlikely that linguistic traces can be detected that far back. From the present study it seems unlikely that a linguistic connection between the Sandawe and the Khoe-speaking San groups in Botswana was associated with the LOd3 lineage. Although LOd3 was the exclusive L0d lineage in the Sandawe, it was almost completely absent in the northern and central Khoisan-speaking groups. In contrast to this absence in the northern and central groups, the southern groups contained higher LOd3 frequencies and the frequencies were the highest is in the Karretjie People from Colesberg. Furthermore L0d3 sequences were detected in a Bantu-speaking individual from Mozambique [61,62] as well as an individual from northern Kenya [63] and an individual from Kuwait [12]. This suggests an L0d3 spread along the eastern part of Africa, forming a connection between the southeastern Khoe-San groups and the Tanzanian Sandawe rather than between the northwestern Khoe-San groups and the Sandawe as the linguistic connection seems to suggest.

BSP analysis (Figure 4 and Additional file 2: Figure S9) indicated that the southern African LOd3 shows a steady decline from the coalescence point onwards with a sharp increase starting at $\sim 2 \mathrm{ka}$. When the east African sequences were included, the decrease was not as severe and the recent expansion started earlier (at $\sim 4 \mathrm{ka}$ ) (Additional file 2: Figure S9). The recent expansion phases of the haplogroup correlates with the introduction of pastoralism in east Africa and southern Africa, respectively. It is therefore likely that the populations that carried LOd3 either adopted the herding economy or benefited from it. In South Africa the introduction of pastoralism is associated with the ceramic final LSA, the only Stone Age phase that also has ceramics and domesticated animal remains in its assemblages [41,57], and although a few such sites date to just before $2 \mathrm{ka}$ [64], most post-date this age. It is notable that not all archaeological assemblages post-dating $\sim 2 \mathrm{ka}$ has ceramics or evidence of domesticated animals. From the archaeological record it seems that bona fide huntergatherer groups have co-inhabited the landscape with early herders [65].

Most other haplogroups also showed expansions during the time of the introduction of pastoralism to the southern parts of Africa. An exception was haplogroup L0d1a that showed a decrease during this time. This decrease could be due to drift or could indicate that the groups carrying L0d1a in high frequencies were negatively affected by this stage. It is historically known that 
when pastoralists enter a territory, hunter-gatherers are displaced to fringe areas, which is unsuitable for stockkeeping. This would impact on the success of the hunter-gatherer population measured through population growth. From this it is deduced that carriers of L0d1a could have been populations that continued their hunter-gatherer lifeway and did not adopt pastoralism or enter in to favorable relationships with pastoralists. Initially L0d1c also started to decline, similar to L0d1a, but then started to increase. This turnaround might be associated with the recent partial adoption of pastoralism practices in the !Xun, through beneficial contracts with Bantu-speakers [3].

Frequencies of some LOd sub-haplogroups (LOd2b, LOd2c, LOd2d, LOdx) were too low to extract any information regarding their history. LOd2b was detected at very low frequencies in the present study (six sequences that represents four haplotypes) (Figure 3 and Additional file 2: Figure S4). It was also not detected previously in the !Xun, Khwe or Ju/'hoansi [9,11]. L0d2c were found at lower frequencies overall (Figure 3 and Additional file 2: Figure S4) with the highest frequencies in the $\neq$ Khomani and Nama (in other populations it was $<5 \%$ of LOd/k haplogroups). A star-like expansion pattern in the network seemed to be associated with the $\neq$ Khomani group (Figure 2) but expansion hypothesis was rejected in the mismatch distribution and only one neutrality test detected evidence for an expansion (Additional file 1: Table S3 and 3). The star-like pattern of a very recent expansion in the network could, however, be observed in the mismatch graph (Additional file 2: Figure S8). This recent expansion in LOd2c correlated temporally with the recent expansions in other haplogroups and is likely to be associated with the introduction of pastoralism. Haplotypes that can be classified as LOd2d were reported previously in Bantu-speakers [61,62] and in the !Xun/Khwe [10]. In the present study L0d2d was confined to the Ju/'hoansi, where it represented $5 \%$ of LOd/k haplogroups (Figure 3 and Additional file 2: Figure S4). LOdx was found only in the two northern-most groups, Khwe (11\%) and !Xun (4\%) (Figure 3 and Additional file 2: Figure S4). LOdx was the only LOd haplogroup found in the Khwe. In the study of Chen et al., LOdx was found at similar frequencies in the !Xun (6\%) but at much higher frequency in the Khwe (42\%), where it also was the only LOd haplogroup [9]. From the network (Figure 2) it is evident that the Khwe all belong to one haplotype and a !Xun haplotype was ancestral to the Khwe haplotype. It therefore seemed that LOdx was an original !Xun haplotype and, through gene-flow, was assimilated into the Khwe. This was the reverse situation as was seen for Lok. The frequencies of LOdx was, however, very low and more LOdx haplotypes need to be sampled before any deductions can be made with certainty (the !Xun and Khwe
L0dx haplotypes reported in Chen et al., [9] did not include the 16399 and 574 regions (Figures 2 and 3) and therefore could not be resolved further).

On a geological timescale, the divergence of the LOK haplogroup (75 ka) coincides with the beginning of marine isotope stage (MIS) 4 that is associated with a cold to very cold phase, not dissimilar to the LGM or MIS 2 (at $\sim 32-13 \mathrm{ka}$ ), which could have contributed to the isolation of population groups and the divergence LOK lineage form other mtDNA lineages. In the present study, L0k was only found in the northern Khoe-San groups (Figure 1 and Additional file 2: Figure S4). The L0k1 haplotypes found in the Nama (low frequencies) is likely the result of recent gene flow from the San people of northern Namibia (such as the Ju/'hoansi and !Xun), since the Nama originated in the Northern Cape Province (SA), more or less where the $\neq$ Khomani groups are located today, and only recently moved into central and northern Namibia [3]. The frequencies of LOk in the !Xun and Khwe from this study (27\%, 28\%) were comparable with previous studies (Additional file 2: Figure S4 and Additional file 1: Table S1). Our results for the Ju/'hoansi (24\% Lok and $71 \%$ LOd), differed somewhat from previous findings for this population (4\% L0k1 and 96\% L0d [11]). The two Ju/'hoansi groups were, however, not from the same locations, the group of the present study was sampled in Tsumkwe (Namibia) and the previously published group was sampled in Botswana (Dobe) as well as in Namibia. It is possible that the Tsumkwe group had more gene-flow with the neighboring !Xun groups.

Since previous studies only reported on the mtDNA haplogroup frequencies of the three northern San groups (!Xun, Khwe and Ju/'hoansi) the low frequency of L0k1 in the Khoe and the absence in the southern San and Coloured groups have never been noted before. Salas et al., however, noted its complete lack in southeastern-Bantu-speakers contrasting with L0d [61]. Previously, it was thought that the history of LOd and LOk is closely intertwined and synonymous with Khoe-San history $[12,61,66]$. From the present study it was clear that, although all groups in this study with Khoe-San ancestry had L0d in common, L0k was only associated with the northern Khoe-San groups (Figures 1. 2, 3, Additional file 2: Figure S4).

The history of the L0k1 haplogroup might be closely tied up with the Khwe rather than the rest of the San groups. It was the haplogroup with the highest frequency in the Khwe, whereas in the other northern San groups (!Xun and Ju/'hoansi) it was secondary to LOd groups (Figures 1 and 3) and might have been introduced to these groups through gene flow with the Khwe and related groups. The low L0k1 haplogroup diversities suggest only few founders (Figure 1). In the network and 
tree (Figure 2 and Additional file 2: Figure S3b) it could be seen that all the Khwe sequences belonged to one haplotype and that the Khwe haplotype was ancestral to the haplotypes observed in the !Xun, Ju/'hoansi and Nama. This suggests that Lok1 was originally a Khwe haplogroup, and spread to the other northern San groups from where it diverged further. In the study by Chen et al., L0k1 also was the predominant haplogroup in the Khwe (Additional file 1: Table S1) [9]. Furthermore, all seven L0k1 sequences identified in the Khwe by Chen et al., was identical to the L0k1 Khwe haplotype of the present study, whereas ten of the eleven L0k1 sequences in the !Xun was derived from the ancestral Khwe haplotype (one !Xun sequence had the ancestral Khwe haplotype) [9].

It is unclear where the Khwe originally came from. They could be Khoe-San groups with extensive Bantuspeaking admixture, Bantu-speakers that lost their cattle, another pastoralist population closely related to Bantuspeakers who occupied the region before the Bantuspeaker expansions, or perhaps a mixture of various refugee groups driven from the grazing grounds into the Okavango swamps [67]. Genetic results from this study indicate that the maternal lineages of the Khwe showed contributions from southeastern Bantu-speakers and Khoe-San (Additional file 2: Figures S2 and S4). In addition they might have had a unique contribution from an unknown pastoralist or hunter-gatherer population that carried high frequencies of the L0k1 maternal lineage, whose identity has since been lost. The discovery of the L0k2 haplogroup in an individual from Yemen [12] suggests that the L0k haplogroups might have had an extensive spread in prehistoric Africa, but remnants of the haplogroup in other populations have been lost due to drift or has not been detected due to insufficient sampling. Alternatively, it could be the result of a more recent introduction as part of the African Diaspora, for example the slave trade.

Ancient hunter-gatherer populations that lived northeast of the Khoe-San groups, prior to the spread of the Bantu-speaking-groups might have been carriers of L0k haplogroups. These groups might have had linguistic and genetic connections with both the KhoeSan and East and Central African hunter-gatherers. An ideal candidate for such a group might be the Pygmy groups that lived north of the Khoe-San before the Bantu-speaker expansions. MtDNA studies, however, found no L0d or L0k haplogroups in the Pygmy groups of central Africa that has been studied thus far [68]. Currently Pygmy groups are mostly assigned to a specific L1c haplogroup. The remnants of the southern Ba-Twa Pygmies have, however, not been studied genetically and it is possible that they might contain maternal genetic connections to the Khwe.
In addition to the L0d/k groups in the Khoe-San and Coloured groups there were also a contribution of haplogroups resulting from admixture from Bantuspeakers and Eurasian groups (Figure 1 and Additional file 2: Figure S2). From the groups that represent the people with southern Khoe-San ancestry, the Karretjie People and $\neq$ Khomani groups had almost exclusive LOd maternal lines, while the Coloured group from the Northern Cape also had very high percentages of LOd. The Coloured group with the largest proportion of admixture was the sample group from Wellington, with 20\% Eurasian admixture and 35\% Bantu-speaking admixture. The Colesberg Coloured group also had large proportions of Bantu-speaking (27\%) and Eurasian (8\%) admixture. The Coloured group from the Northern Cape had 5\% Eurasian admixture and 2.5\% Bantu-speaking admixture. The three Coloured groups were the only groups with Eurasian admixture, the admixture in the remaining Khoe-San groups were due to gene-flow with the Bantu-speaking groups (Figure 1 and Additional file 2: Figure S2).

The Khwe group had the largest input from Bantuspeaking groups (61\%) with two of the most common southeastern Bantu-speaking associated haplogroups, L2a and L3e constituting the largest part (22\% each) (Figure 1 and Additional file 2: Figure S2). The Nama had 21.5\% Bantu-speaker admixture and in this case the Bantu-speaker-admixture was indicative of admixture with southwestern Bantu-speakers (L1c, L3d and L3f haplogroups). The remaining San groups had $<10 \%$ Bantu-speaker admixture (Figure 1 and Additional file 2: Figure S2).

\section{Genetic affinities of Khoe, San and Coloured groups with neighboring groups}

Using the maternally transmitted mtDNA marker, the affinities between the present day Khoe-San and some Coloured groups were examined. Since the associated haplogroups of the Bantu-speakers and non-African groups are very distinct from those commonly found in the Khoe-San, admixture from these populations will have a great influence in the resultant tree that represents relationships between the different population groups. This can be seen in Figure 5A where the Bantuspeaking admixture in the Cape Coloured and Khwe groups cause them to group within the Bantu-speakingclade. While an inclusive comparison is representative of the current genetic composition of the groups studied, it should not be used to make inferences about Khoe-San history and Khoe-San group relations before the expansions of Bantu-speakers and the influx of non-Africans.

In an attempt to infer group relations between the Khoe-San and the Khoe-San ancestors of some Coloured groups that existed before the influx of other groups, 
haplogroups associated with Bantu-speakers as well as non-African haplogroups were removed from the Khoe-San and sampled Coloured groups. Remaining Khoe-San associated haplogroups (LOd and LOk) were then used to infer relationships that might have existed in the past between the Khoe-San groups. The resulting tree (Figure 5B) showed that the southern groups were closely associated with each other while the northern groups are separate from the southern groups. The Khwe was different from all the groups. There was an association between geographic and genetic distance (Figure 5B), and it was stronger than the situation where Bantu-speaking and non-African haplogroups were included (Figure 5A). Due to the possibility that L0k was not part of the original Khoe-San haplogroup pool but rather introduced by other huntergatherer groups that were displaced (such as previously discussed for the Khwe) or because of the Bantu-speaker expansions, L0k was also removed and only LOd based group relations was tested (Figure 5C). Interestingly, the $\mathrm{Ju} /$ 'hoansi group moved closer to the southern groups due to the higher frequency of L0d1b and the lower frequency of LOd1c. The correlation between physical and genetic distance remained for the LOd based group comparison. Using the present day distribution of haplogroup lineages within a population group as proxy for historical relations is debatable, since group memberships are, and have been, fluid and might be more so for certain population groups than others. Furthermore, inferences based on one locus, such as mtDNA, is very susceptible to the effects of genetic drift on lineages. Certain major cultural shifts that occurred in the past, such as the adoption/introduction of pastoralism by Khoe groups might also have had a significant impact on haplogroup distribution patterns.

\section{Conclusion}

The following deductions can be made about the maternal line genetic composition of the population groups included in the study. First, various levels of admixture from both Bantu-speakers and non-African groups are present in the different Khoe-San and some Coloured groups. Secondly, the Khwe group is different from the other Khoe-San and Coloured groups and might represent remnants of another extinct hunter-gatherer group that were displaced by the Bantu-speaking expansions and became associated with the San. Thirdly, there is a distance-based genetic relationship between the remaining Khoe-San groups. Fourth, the haplogroup distribution between the southern and northern groups is different and the pastoralist Khoe group, the Nama, clusters with, and is similar to, the southern groups.
Overall this study presents new insights into how mtDNA haplogroups and their distribution among southern African populations were used to reconstruct the demographic histories of Khoe-San and selected Coloured populations. The juxtaposition of archeological and linguistic data, where possible, in conjunction with the genetic data, provided a broad context for reconstructing the human past of the southern African region.

\section{Methods \\ Subjects}

DNA samples from 538 unrelated individuals were collected with the subjects' informed consent, and the project was approved by the Human Research Ethics Committee (Medical) at the University of the Witwatersrand, Johannesburg (Protocol Number: M050902), the Working Group of Indigenous Minorities in Southern Africa (WIMSA) and the South African San Council. During sample collection, information regarding birthplace, relationship to other volunteers, home language and ethnic group were recorded. An interpreter was used during sample collections where the volunteers did not speak English or Afrikaans as a first or second language. A description of sample groups, group codes, place of sampling and origin, linguistic grouping and number of individuals are outlined in Table 1 and a map with sample locations is given in Additional file 2: Figure S1.

\section{DNA extraction}

DNA was extracted from EDTA-blood using the saltingout method [69] and from buccal swabs using the PureGene ${ }^{\circledR}$ Genomic DNA Purification Kit (Gentra Systems) according to manufacturer's instructions.

\section{MtDNA typing}

MtDNA types were assigned to macro-haplogroups L0-L6, $\mathrm{M}, \mathrm{N}$ and $\mathrm{R}$ using a minisequencing method [70]. The mtDNA control region was amplified and sequenced according to previously published methods [71] with some modification [70]. Sequence data were obtained for hyper variable segments I (HVS I; nucleotide positions 1599716569) and HVS II (nucleotide positions 57-607). The base calls at positions $16184-16193$ were ascertained by manual inspection of electropherograms and where there was any uncertainty about a mutation, the sequence was repeated with the reverse primer. Variation in the HVS-II 303-315 repeat track were not considered or reported in any of the analyses. Insertions in the poly $\mathrm{C}$ repeat track at position 568-573 where always taken as a $1 \mathrm{bp} \mathrm{C}$ insertion. When there was uncertainty whether a mutation in the 16184-16193 region was the result of a substitution or an in-del, the mutation was always treated as a substitution. All other regions were considered albeit some regions were sometimes differentially weighted as outlined in the 
individual analysis descriptions. Insertions or deletions were treated as a fifth state. Sequences were aligned using the Clustal W algorithm [72] implemented in BioEdit v.7.0.5.3 [73]. All sequences were compared to the revised Cambridge reference sequence [74] to establish the variant positions and were assigned to haplogroups according to the proposed nomenclature [12]. Combined HVS I and II sequences were used in further analyses. All sequences were submitted to Genbank (Accession numbers KC004766 - KC005303 for HVS I and KC004228 KC004765 for HVS II sequences).

\section{Comparative data}

Sequences from other sources included a Neanderthal sequence (Genbank accession number: NC_011137) [75], the revised Cambridge reference sequence [74] and additional published L0d3 sequences [10,12,31]. Sequences from [31] and [10] had overlap in some of the subjects and only one of the two in each case was selected. Problems with Genbank submissions from [31] were mentioned previously $[17,76]$. A complete description on sequences included from these two publications are found in [17] (especially note the explanation regarding isolate TZSW084).

\section{Computational analyses}

Full details and parameters of computational analyses are included in the supplementary methods section (Additional file 3). The analyses included a maximum likelihood tree of all unique haplotypes; and furthermore, for LOd and L0k haplogroups and sub-haplogroups: a Median Joining network, TMRCA calculations, Mismatch distributions, isofrequency plots of the geographic distribution, Bayesian Skyline Plots (BSP) and various summary statistics and neutrality tests. For the population groups in the study, population pairwise Fst's were calculated, visualized as trees and compared to geographic distances between populations using linear regressions and Mantel tests (groups with $\mathrm{N}<10$ were excluded from the population analyses - Table 1).

\section{Additional files}

Additional file 1: Table S1. Published mtDNA haplogroup and subhaplogroup frequencies in San populations. Table S2. TMRCA calculated for the LOd/k subgroups. Four different mutation rates are applied. Table S3. Mismatch distribution statistics. Table S4. Mitochondrial population pairwise Fst values (All sequences).

Additional file 2: Figure S1. Map indicating the place of origin for the Coloured, Khoe and San individuals who participated in the study. Labels and further information are available in Table 1. Bantu-speakers and people of non-African descent were sampled from various locations in South Africa and are not indicated on the map. Figure S2. Bar plot of percentage mtDNA haplogroup assignment in study populations. Figure S3a. Maximum likelihood tree representing the substructure of $L 1$ to $L 5$. A Neanderthal sequence forms the outgroup. Branch support (\%) was calculated through aLRT. Figure S3b. Maximum likelihood tree showing the relationships of the different mtDNA haplotypes within haplogroup LO. A Neanderthal sequence forms the outgroup. Branch support (\%) was calculated through aLRT. Figure S4. Bar plot of percentage LOd/k subhaplogroup assignment in study populations. Published comparative data is according to Table S1. Figure S5. Graphic representation of coalescent times and times of divergence of the mtDNA sub-haplogroups of LOd and LOK (according to Table 2). The mutation rate estimated by Ward et al., (1991) was used in these estimates. Figure S6. Contour plots indicating the frequency distributions of LOd/k subgroups. Figure S7. Contour plots of LOd1C split into two subgroups, LOd1C1 and the remaining LOd1C sequences (LOd1c-). Figure S8. Mismatch distributions of LOd/k subhaplogroups and comparative groups. \# expansion hypothesis rejected (95\% Cl overlap). Figure S9. Bayesian Skyline plots of LOd haplogroups showing changes in $N_{e}$ through time. $N_{e}$ is represented on the $Y$-axis, while years before present are represented on the $X$-axis, with the present indicated by 0 . LOd3+ is LOd3 including the east African and Kuwait sequences. LOd3- includes only LOd3 sequences from the present study. The black bold vertical lines indicate the coalescence date and the lighter vertical lines the $95 \%$ confidence intervals for the coalescence. The blue lines indicate the 95\% confidence intervals for the plot-lines. Figure S10. Bayesian Skyline plots of all LOd haplotypes across all population groups, showing changes in $N_{e}$ through time. $N_{e}$ is represented on the $Y$-axis, while years before present are represented on the $X$-axis, with the present indicated by 0 . The black bold vertical lines indicate the coalescence date and the lighter vertical lines the 95\% confidence intervals for the coalescence. The blue lines indicate the 95\% confidence intervals for the plot-lines. Figure S11. LOd3 branch after adding comparative published sequences. Tanzanian (dark green), Kuwait (Purple), other colours according to Figure 2. Yellow clade - southern African branch. Light green clade - Tanzanian and Kuwait branch.

Additional file 3: Supplementary Methods.

\section{Competing interests}

The authors have no financial or other competing interests to declare

\section{Authors' contributions}

CMS and HS conceived of the study and participated in the sample collections. CMS carried out the molecular laboratory work, sequence processing and downstream computational and statistical analyses. CMS drafted and wrote the manuscript. HS participated in the design and coordination of the study and commented on the manuscript. ML contributed archaeological and marine isotope contexts. All authors read and approved the final manuscript.

\section{Acknowledgements}

We are grateful to all subjects who participated in our research and would like to thank members of the Working Group of Indigenous Minorities in Southern Africa (WIMSA) and the South African San Council for facilitating research amongst the San people. We would also like to acknowledge Prof. Michael De Jongh from the University of South Africa (UNISA) who participated in and facilitated the sample collection among the Karretjie People and Professor Trefor Jenkins and colleagues in the Division of Human Genetics for assistance with other fieldwork and processing of samples. This study was supported by grants awarded to HS from the South African Medical Research Council and the National Research Foundation; HS and CS from the National Health Laboratory Service Research Trust; and CS was supported by the National Research Foundation (SA) and the Wenner-Gren Foundation (Sweden).

\section{Author details}

${ }^{1}$ Human Genomic Diversity and Disease Research Unit, Division of Human Genetics, School of Pathology, Faculty of Health Sciences, University of the Witwatersrand and the National Health Laboratory Service, Johannesburg 2000, South Africa. ${ }^{2}$ Department of Evolutionary Biology, Evolutionary Biology Centre, Uppsala University, Norbyvägen 18D, Uppsala, SE 752 36, Sweden. ${ }^{3}$ Department of Anthropology and Development Studies, University of Johannesburg, Auckland Park Campus, PO Box 524, Johannesburg 2006, South Africa. 


\section{References}

1. Schlebusch C: Issues raised by use of ethnic-group names in genome study. Nature 2010, 464(7288):487. author reply 487.

2. Crawhall N: Languages, genetics and archaeology: problems and the possibilties in Africa. In The prehistory of Africa. Edited by Soodyall $\mathrm{H}$. Johannesburg \& Cape Town: Jonathan Ball Publishers; 2006:109-124

3. Barnard A: Hunters and herders of southern Africa - A comparitive ethnography of the Khoisan peoples, Volume 85. Cambridge: Cambridge University Press; 1992.

4. Fauvelle-Aymar FX, Sadr K: Trends and traps in the reconstruction of early herding societies in southern Africa: introduction. South Afr Humanit 2008, 20:1-6.

5. Smith A, Malherbe C, Guenther M, Berens P: The Bushmen of Southern Africa. Cape Town: David Philips Publishers; 2000

6. le Roux W, White A: Voices of the San. Cape Town: Kwela Books; 2004.

7. Güldemann T, Stoneking M: A historical appraisal of clicks: a linguistic and genetic population perspective. Annual Review of Anthropology 2008, 37:93-109.

8. Güldemann T: A linguist's view: Khoe-Kwadi speakers as the earliest foodproducers of southern Africa. In Khoekhoe and the origins of herding in southern Africa, Volume 20 (1). Edited by Sadr K, Fauvelle-Aymar F-X. Pietermaritzburg: Southern African Humanities; 2008:93-132.

9. Chen YS, Olckers A, Schurr TG, Kogelnik AM, Huoponen K, Wallace DC mtDNA variation in the South African Kung and Khwe-and their genetic relationships to other African populations. Am J Hum Genet 2000, 66(4):1362-1383.

10. Tishkoff SA, Gonder MK, Henn BM, Mortensen H, Knight A, Gignoux C, Fernandopulle N, Lema G, Nyambo TB, Ramakrishnan U, et al: History of click-speaking populations of Africa inferred from mtDNA and $Y$ chromosome genetic variation. Mol Biol Evol 2007, 24(10):2180-2195.

11. Vigilant L, Stoneking M, Harpending H, Hawkes K, Wilson AC: African populations and the evolution of human mitochondrial DNA. Science 1991, 253(5027):1503-1507.

12. Behar DM, Villems R, Soodyall H, Blue-Smith J, Pereira L, Metspalu E, Scozzari R, Makkan H, Tzur S, Comas D, et al: The dawn of human matrilineal diversity. Am J Hum Genet 2008, 82(5):1130-1140.

13. Sharp J, Douglas S: Prisoners of their Reputation? The Veterans of the 'Bushman' Battalions in South Africa. In Miscast Negotiating the Presence of the Bushmen. Edited by Skotnes P. Cape Town: UCT Press; 1996:323-329.

14. de Wit E, Delport W, Rugamika CE, Meintjes A, Moller M, van Helden PD, Seoighe C, Hoal EG: Genome-wide analysis of the structure of the south African coloured population in the western cape. Hum Genet 2010, 128(2):145-153.

15. Quintana-Murci L, Harmant C, Quach H, Balanovsky O, Zaporozhchenko V, Bormans C, van Helden PD, Hoal EG, Behar DM: Strong maternal Khoisan contribution to the South African coloured population: a case of genderbiased admixture. Am J Hum Genet 2010, 86(4):611-620.

16. Patterson N, Petersen DC, van der Ross RE, Sudoyo H, Glashoff RH, Marzuki S, Reich D, Hayes VM: Genetic structure of a unique admixed population: implications for medical research. Hum Mol Genet 2010, 19(3):411-419.

17. Schlebusch CM, de Jongh M, Soodyall H: Different contributions of ancient mitochondrial and Y-chromosomal lineages in 'Karretjie people' of the great Karoo in South Africa. J Hum Genet 2011, 56(9): 623-630.

18. Ward RH, Frazier BL, Dew-Jager K, Paabo S: Extensive mitochondrial diversity within a single Amerindian tribe. Proc Natl Acad Sci USA 1991 88(19):8720-8724.

19. Soares P, Ermini L, Thomson N, Mormina M, Rito T, Rohl A, Salas A, Oppenheimer S, Macaulay V, Richards MB: Correcting for purifying selection: an improved human mitochondrial molecular clock. Am J Hum Genet 2009, 84(6):740-759.

20. Forster P, Harding R, Torroni A, Bandelt HJ: Origin and evolution of Native American mtDNA variation: a reappraisal. Am J Hum Genet 1996, 59(4):935-945.

21. Garcea EAA: Successes and failures of human dispersals from North Africa. Quat Int 2012, 270:119-128.

22. Stringer C: Palaeoanthropology. Coasting out of Africa. Nature 2000, 405(6782):24-25, 27

23. Excoffier $L$, Schneider $S$ : Why hunter-gatherer populations do not show signs of pleistocene demographic expansions. Proc Natl Acad Sci USA 1999, 96(19):10597-10602.
24. Tajima F: Statistical method for testing the neutral mutation hypothesis by DNA polymorphism. Genetics 1989, 123(3):585-595.

25. Fu YX: Statistical tests of neutrality of mutations against population growth hitchhiking and background selection. Genetics 1997, 147(2):915-925.

26. Ramos-Onsins SE, Rozas J: Statistical properties of new neutrality tests against population growth. Mol Biol Evol 2002, 19(12):2092-2100.

27. Pilkington MM, Wilder JA, Mendez FL, Cox MP, Woerner A, Angui T, Kingan S, Mobasher Z, Batini C, Destro-Bisol G, et al: Contrasting signatures of population growth for mitochondrial DNA and $\mathrm{Y}$ chromosomes among human populations in Africa. Mol Biol Evol 2008, 25(3):517-525.

28. Shapiro B, Drummond AJ, Rambaut A, Wilson MC, Matheus PE, Sher AV, Pybus OG, Gilbert MT, Barnes I, Binladen J, et al: Rise and fall of the Beringian steppe bison. Science 2004, 306(5701):1561-1565.

29. Atkinson QD, Gray RD, Drummond AJ: mtDNA variation predicts population size in humans and reveals a major Southern Asian chapter in human prehistory. Mol Biol Evol 2008, 25(2):468-474.

30. Drummond AJ, Rambaut A, Shapiro B, Pybus OG: Bayesian coalescent inference of past population dynamics from molecular sequences. Mol Biol Evol 2005, 22(5):1185-1192.

31. Gonder MK, Mortensen HM, Reed FA, de Sousa A, Tishkoff SA: WholemtDNA genome sequence analysis of ancient African lineages. Mol Biol Evol 2007, 24(3):757-768.

32. Knight $A$, Underhill PA, Mortensen HM, Zhivotovsky LA, Lin AA, Henn BM, Louis D, Ruhlen M, Mountain JL: African Y chromosome and mtDNA divergence provides insight into the history of click languages. Curr Biol 2003, 13(6):464-473.

33. Mitchell PJ: The Archaeology of Southern Africa. Cambridge: Cambridge University Press; 2002.

34. Marean CW, Bar-Matthews M, Bernatchez J, Fisher E, Goldberg P, Herries Al, Jacobs Z, Jerardino A, Karkanas P, Minichillo T, et al: Early human use of marine resources and pigment in South Africa during the Middle Pleistocene. Nature 2007, 449(7164):905-908.

35. Henshilwood CS, d'Errico F, van Niekerk KL, Coquinot Y, Jacobs Z, Lauritzen SE, Menu M, Garcia-Moreno R: A 100,000-year-old ochre-processing workshop at Blombos Cave, South Africa. Science 2011, 334(6053):219-222.

36. Wadley L, Sievers C, Bamford M, Goldberg P, Berna F, Miller C: Middle Stone Age bedding construction and settlement patterns at Sibudu, South Africa. Science 2011, 334(6061):1388-1391

37. d'Errico F, Backwell L, Villa P, Degano I, Lucejko JJ, Bamford MK, Higham TF, Colombini MP, Beaumont PB: Early evidence of San material culture represented by organic artifacts from Border Cave, South Africa. Proc Natl Acad Sci USA 2012, 109(33):13214-13219.

38. Schlebusch CM, Skoglund P, Sjodin P, Gattepaille LM, Hernandez D, Jay F, Li $S$, De Jongh $M$, Singleton A, Blum MG, et al: Genomic variation in seven khoe-San groups reveals adaptation and complex African history. Science 2012, 338(6105):374-379.

39. Gronau I, Hubisz MJ, Gulko B, Danko CG, Siepel A: Bayesian inference of ancient human demography from individual genome sequences. Nat Genet 2011, 43(10):1031-1034.

40. Veeramah KR, Wegmann D, Woerner A, Mendez FL, Watkins JC, Destro-Bisol G, Soodyall H, Louie L, Hammer MF: An early divergence of KhoeSan ancestors from those of other modern humans is supported by an $\mathrm{ABC}$-based analysis of autosomal resequencing data. Mol Biol Evol 2011, 29(2):617-630

41. Lombard M, Wadley L, Deacon J, Wurz S, Parsons I, Mohapi M, Swart J, Mitchell P: South African and Lesotho stone Age sequence updated (I). South African Archaeological Bulletin 2012, 67:123-144.

42. Wurz S: Variability in the middle stone Age lithic sequence, 115,000 60,000 years ago at klasies river, south Africa. J Archaeol Sci 2002, 29:1001-1015.

43. Wadley L: Compound-adhesive manufacture as a behavioral proxy for complex cognition in the Middle Stone Age. Curr Anthropol 2010, 51:S111-S119.

44. Henshilwood CS, Dubreuil B: The Still Bay and Howiesons Poort, 77e59 ka: symbolic material culture and the evolution of the mind during the African Middle Stone Age. Curr Anthropol 2011, 52:361-400.

45. Henshilwood C, d'Errico F, Vanhaeren M, van Niekerk K, Jacobs Z: Middle Stone Age shell beads from South Africa. Science 2004, 304(5669):404.

46. Henshilwood CS, d'Errico F, Watts I: Engraved ochres from the middle stone Age levels at blombos cave, south Africa. J Hum Evol 2009, 57(1):27-47. 
47. Lombard M, Parsons I: What happened to the human mind after the Howiesons Poort? Antiquity 2011, 85:1433-1443.

48. Mohapi M: Point morphology and the middle stone Age cultural sequence of sibudu cave, KwaZulu-Natal, south Africa. South African Archaeological Bulletin 2012, 67:5-15.

49. Clark JL, Plug I: Animal exploitation strategies during the south African middle stone Age: howiesons poort and post-howiesons poort fauna from sibudu cave. J Hum Evol 2008, 54(6):886-898.

50. Goldberg P, Miller CE, Schiegl S, Ligouis B, Berna F, Conard NJ, Wadley L: Bedding, hearths and site maintenance in the Middle Stone Age of Sibudu Cave, KwaZulu-Natal, South Africa. Archaeological and Anthropological Science 2009, 1:95-122.

51. Lombard M, Parsons I: Fact or fiction? Behavioural and technological reversal after $60 \mathrm{ka}$ in Southern Africa. South African Archaeological Bulletin 2010, 65:224-228.

52. Harper PTN: The middle stone Age sequences at rose cottage cave: a search for continuity and discontinuity. South African Journal of Science 1997, 93:470-475.

53. Soriano S, Villa P, Wadley L: Blade technology and tool forms in the middle stone Age of south Africa: the howiesons poort and posthowiesons poort at rose cottage cave. J Archaeol Sci 2007, 34:681-703.

54. Vogelsang R, Richter J, Jacobs Z, Eichhorn E, Linseele V, Roberts R: New excavations of middle stone Age deposits at Apollo 11 rockshelter, Namibia: stratigraphy, archaeology, chronology and past environments. Journal of African Archaeology 2010, 8:185-218.

55. Lewis-Williams JD, Pearce DG: San spirituality: roots, expressions and social consequences. Cape Town: Double Storey Books; 2004.

56. Ramirez-Soriano A, Ramos-Onsins SE, Rozas J, Calafell F, Navarro A: Statistical power analysis of neutrality tests under demographic expansions, contractions and bottlenecks with recombination. Genetics 2008, 179(1):555-567.

57. Deacon J: The Later Stone Age of Southernmost Africa. Oxford: British Archaeological Reports International Series 213; 1984

58. Deacon HJ, Deacon J: Human Beginnings in South Africa. Uncovering the Secrets of the Stone Age. Cape Town and Johannesburg: David Philip Publishers: 1999.

59. Pannell JR, Charlesworth B: Effects of metapopulation processes on measures of genetic diversity. Philos Trans R Soc Lond B Biol Sci 2000, 355(1404):1851-1864.

60. De Almeida A: Bushmen and other non-Bantu peoples of Angola. Johannesburg: Witwatersrand University Press for the Institute for the Study of Man in Africa; 1965.

61. Salas A, Richards M, De la Fe T, Lareu MV, Sobrino B, Sanchez-Diz P, Macaulay V, Carracedo A: The making of the African mtDNA landscape. Am J Hum Genet 2002, 71(5):1082-1111.

62. Pereira L, Macaulay V, Torroni A, Scozzari R, Prata MJ, Amorim A: Prehistoric and historic traces in the mtDNA of Mozambique: insights into the Bantu expansions and the slave trade. Ann Hum Genet 2001, 65(Pt 5):439-458.

63. Watson E, Forster P, Richards M, Bandelt HJ: Mitochondrial footprints of human expansions in Africa. Am J Hum Genet 1997, 61(3):691-704.

64. Sadr K, Sampson CG: Through thick and thin: early pottery in southern Africa. Journal of African Archaeology 2006, 4:235-252.

65. Parsons I: Hunter-gatherers or herders? reconsidering the swartkop and doornfontein industries, northern cape province, south Africa. Before Farming 2007, 3:1-10.

66. Atkinson QD, Gray RD, Drummond AJ: Bayesian coalescent inference of major human mitochondrial DNA haplogroup expansions in Africa. Proc Biol Sci 2009, 276(1655):367-373.

67. Cashdan E: Hunter-gatherers of the northern Kalahari. In Contemporary Studies on Khoisan, Volume 1. Edited by Vossen R, Keuthmann K. Hamburg: Helmut Buske Verlag; 1986:145-180

68. Quintana-Murci L, Quach H, Harmant C, Luca F, Massonnet B, Patin E, Sica L, Mouguiama-Daouda P, Comas D, Tzur S, et al: Maternal traces of deep common ancestry and asymmetric gene flow between Pygmy huntergatherers and Bantu-speaking farmers. Proc Natl Acad Sci USA 2008, 105(5):1596-1601.

69. Miller SA, Dykes DD, Polesky HF: A simple salting out procedure for extracting DNA from human nucleated cells. Nucleic Acids Res 1988, 16(3):1215.

70. Schlebusch CM, Naidoo T, Soodyall H: SNaPshot minisequencing to resolve mitochondrial macro-haplogroups found in Africa. Electrophoresis 2009, 30(21):3657-3664.
71. Behar DM, Rosset S, Blue-Smith J, Balanovsky O, Tzur S, Comas D, Mitchell RJ, Quintana-Murci L, Tyler-Smith C, Wells RS: The Genographic Project public participation mitochondrial DNA database. PLoS Genet 2007, 3(6):e104.

72. Thompson JD, Higgins DG, Gibson TJ: CLUSTAL W: improving the sensitivity of progressive multiple sequence alignment through sequence weighting, position-specific gap penalties and weight matrix choice. Nucleic Acids Res 1994, 22(22):4673-4680.

73. Hall TA: BioEdit: a user-friendly biological sequence alignment editor and analysis program for Windows 95/98/NT. Nucl Acids Symp Ser 1999, 41:95-98.

74. Andrews RM, Kubacka I, Chinnery PF, Lightowlers RN, Turnbull DM, Howell N: Reanalysis and revision of the Cambridge reference sequence for human mitochondrial DNA. Nat Genet 1999, 23(2):147

75. Green RE, Malaspinas AS, Krause J, Briggs AW, Johnson PL, Uhler C, Meyer M, Good JM, Maricic T, Stenzel U, et al: A complete Neandertal mitochondrial genome sequence determined by high-throughput sequencing. Cell 2008, 134(3):416-426.

76. Yao YG, Salas A, Logan I, Bandelt HJ: mtDNA data mining in GenBank needs surveying. Am J Hum Genet 2009, 85(6):929-933. author reply 933.

doi:10.1186/1471-2148-13-56

Cite this article as: Schlebusch et al:: MtDNA control region variation affirms diversity and deep sub-structure in populations from southern Africa. BMC Evolutionary Biology 2013 13:56.

\section{Submit your next manuscript to BioMed Central and take full advantage of:}

- Convenient online submission

- Thorough peer review

- No space constraints or color figure charges

- Immediate publication on acceptance

- Inclusion in PubMed, CAS, Scopus and Google Scholar

- Research which is freely available for redistribution

Submit your manuscript at www.biomedcentral.com/submit
C BioMed Central 